\title{
التحولات التربوية في مجتمع المعرفة
}

\begin{tabular}{|c|c|}
\hline \multicolumn{2}{|c|}{ اعهلداد } \\
\hline د. حاتم فرغلي ضاحي جاد & أ.د سعيد ا سماعيل عثمان \\
\hline مدرس أصول التربية & أستاذ أصول التربية وعميد الكلية السابق \\
\hline كلية التربية- جامعة أسوان & كلية التربية- جامعة أسوان \\
\hline
\end{tabular}

أ أبيد عباس عثمان

باحث دكتوراه أصول التربية

كلية التربية- جامعة أسوان 


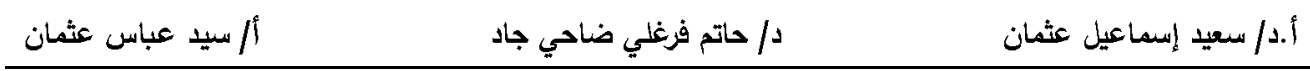

\section{المستخلص :}

هافت الدراسة لحالية إلى التعرف على متطلبات الولوج الى مجتمع المعرفة ووضع

هر بالنسبة لمجتمع المعرفة، ولتحقيق هذا الهدف تناوت بالتحليل متطلبات التحول التربي

في مجتمع المعرفة ومؤتمر بالنسبة لاستيفاء متطلبات مجتمع المعرفة. وتوصلت

الدراسة إلى أنه لكي يتم التحول التربي في مجتمع المعرفة ينبني زيادة الإنفاق على التعليم والتوسع في مفهوم المدرسة الذكية، والاستخدام الفعال لتكنولوجيا المعلومات، توسيع الشاركة المجتمعية. الكلمات المفتاحية: مجتمع المعرفة - التحولات التربوية . 


$$
\text { التحولات التربوية في مجتمح المعرفة }
$$

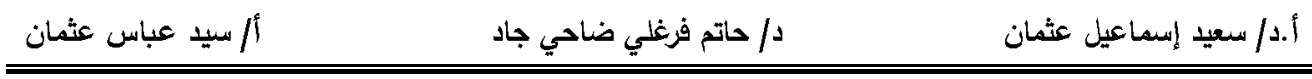

Educational Transformation in Knowledge Society

Prof. Said Ismail Osman

Dr. Hatem Farghaly Dahy

Sayed Abbas Osman

\section{Abstract:}

The current study aimed to recognize the requirements of educational transformation in the knowledge society and Egypt position in knowledge society. The study concluded that to achieve Educational Transformation in Knowledge Society, there must be increase the budget of education, enhance the concept of smart school, active use of information technology and increase the social partnership.

Key words: Knowledge Society - Educational transformation 


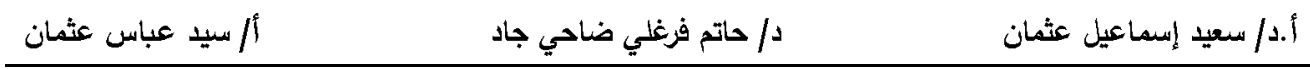

مقدمة

لقد تعددت الأسماء التي أطلقها العماء والمفكرون على المجتمع في للصر لحالي، فمنهم أطق عليه مجتمع المعلومات، وهناك من أسماه بمجتمع ما بعد لصناعة ومجتمع ما بعد لحداثة، ومجتمع عصر لحلب الآلي والإنترنت، ومجتمع ثورة المعلومات والأصالات، ومجتمع الإصداد المعرفي، ومع تلك تبقي تمية هذا المجتمع بمجتمع المعرفة التسمية الأدق و الأكثر شيوعا. إذ أن المعرفة تعد لسب الرئي لما شهده التاريخ الإنساني من نقلة صضارية نوعية، أحدث تغيرات هائلة في لحياء البشرية.

فجتمع المعرفة يجد أحد أنملطنور لهـارة الإنسانية، التي بدأت مراحلها باكثشاف الإنسان الزراعة، فظهر المجتمع الزراعي، التي يعد ثطة لطلاق لمضارة البشرية، ثمظهر المجتمع لهناعي، التي اعتمد على للصنع والآلة، ومع تظور التاريخ الإساني وما حدث لثن من ثورة تكنولوجية ومعلوماتية أقام الإنسان مجتمع المعلومات، ومن ثم مجتمع المعرفة التي يعتمد بثكل رئيسي على سيادة توليد المعرفة وتداولها وهن توظيفها في مياين لحياة المختلفة. ولقد أكدت بخ التقارير المحلية والعربية والدولية على أهمية ولوجصر، والدول والدول العربية بصفة عامة إلى مجتمع المعرفة، والهشاركة فيه بفاعلية من خلال إنتاج إنتاج وتوليد معرفة جديدة، وعدم الإكار على الاستفادة من المعرفة المتاحة، كما ركزت هذه التقارير على ضرورة العل على تقلف القجوة المعرفية بين الدول العربية العربية والدول المتقدمة وإقامة مجتمع المعرفة، كما أشارت هذه التقارير إلى أهمية الانتقال من الإهاد التقليني إلى الهـاد المعرفة، ورصدت انعكاسات مجتمع المعرفة المعرفة على العملية التعليمية، كما أوصت بتحقيق المتطلبات التربوية لمجتمع المعرفة، المعرفة، عبر تطوير منظومة التعليم بكافة محتوياتها، وفي مقدمة تلك تطوير المناهج 


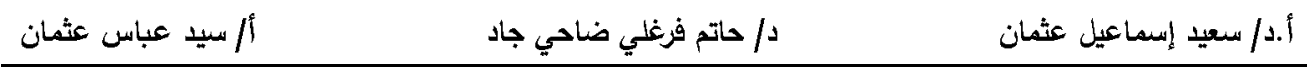

المناهج التعليمية بما يتوقت مع ما تفرضه تحديات مجتمع المعرفة، وإحداث التغيرات التغيرات والإصلاحات المطلوبة في أدوار الممارسين التربويين بما يمق الششاركة الفعالة في مجتمع المعرفة. (تقرير اليونسكو ه . . r)، و(تقرير التنمية البشرية مصر

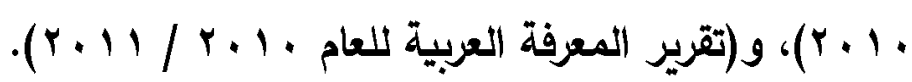
وسيتم تناول التحولات التربوية في مجتمع المعرفة من خلال عرض مجتمع المعرفة ناحية المفهوم، ومراحل الطور، ولثهط، والمؤشرات، بالإضافة إلى جهودمر للتحول نحو مجتمع المعرفة.

\section{1 ـ مفهوم مجتمع المعرفة المجة}

بالرغم من لحداثة النسبية لمفهوم "مجتمع المعرفة" إلاع أنه حظي باهتمام العديد من

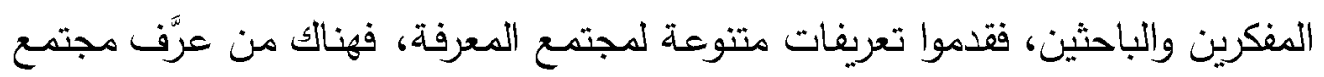
المعرفة كونه المجتمع التي يهتم بجمع وتوظف المعرفة، ومنهم من تتاول في تعريفه سمات هذا المجتمع، كما ركز الب على ارتباط هذا المجتمع بتكنولوجيا المعلومات، وهناك من

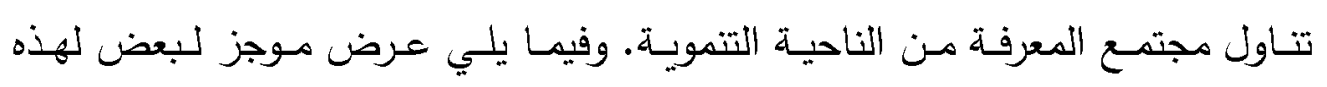
التعريفات.

تعريفات تناولت مجتمـع المعرفة علي أنـه ذلك المجتمع الذي يهتم بجمع وتوظيف المعرفة واستخدامها في عملية التنمية: وبناء علي للك يعرف حيدر مجتمع المعرفة بأنه: "المجتمع القائم علي نشر المعرفة, وإنتاجها, وتوظيفها بكفاءة في جميع مجالات النشاط المجتمي: في الاقتصساد, وفي المجتمع المدني, وفي السياسة, وفي الحياة الخاصـة, وذلك للارتقاء بالحالة الإنسانية".

$$
\text { (حيدر، عبد اللطيف، ؛ . . r، 1. 7. }
$$

فجتمع المعرفة هو لآك المجتمع الني يقرر بناء سياساته وإستراتيجياته المستقبلية المستقبلية واتخاذ قرا راته، استنادا إلى حالة معرفية أصيلة، وهو المجتمع الني يسعى بكل 


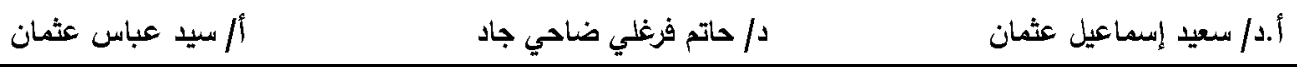

بكل جدية إلى إنتاج المعرفة، ونشرها وتوظيفها، للإفادة منها في المجالات كافة،

$$
\text { وبخاصة المجالات الحياتية. (الصرايرة، عحم، ل + + r، ب) }
$$

وبالتالي فإن مجتمع المعرفة هو المجتمع الذي يهتم بلورة المعرفة، ويوفر البيئة

المناسبة لتفعيلها وتنشيطها وزيـادة عطائها، بما في ذلك البيئة التكنولوجية الحديثة بشكلها العام، وبيئة تكنولوجيا المعلومات على وجه خاص، بما يسهم في تظوير امكانات امكانات الإنسان، وتعزيز التنمية، والسعي نحو بناء حياة كريمة للجميع، وهو يرتكز بشكل بشكل أساسي على الإبداع الفكري والإنتاج المعرفي في صورة تتجاوز الحدود المكانية (Gilbert, Jane, 2006, المكانية والزمانية، التي اتتصت بها المجتمعات الصناعية.

2006, 32)

تعريفات ركزت على سمات مجتمع المعرفة: وبهذا ينظر إلى مجتمع المعرفـة على أنـه المجتمع القـائم والقـادر على إنتاج واستغلال المعرفة محلياً وتطبيقها ونثرها معتمدة في ذلك على مـا لديه من موارد وإمكانيات ذاتية محلية، علاوة على كون صناعة المعرفةقطاعا اقتصاديا قائما بذاته.

(Brine, Jacky, 2006, 649-66)

فجتمع المعرفة يعد بمثابة منظومة وحركة ديناميكية في الفكر والإبد اع والعمل، من أجل تحقيق التنمية، يتفق ذلك مع توجيهات البنك الدولي فى تقريره عن التنمية الدولية

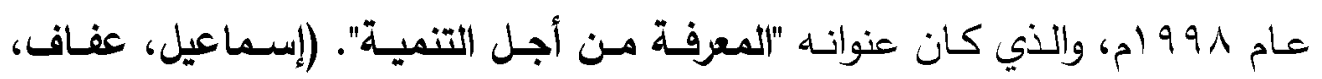

$$
(\Lambda-V, r+\Lambda
$$

تعريفات ركزت على ارتباط مجتمع المعرفة بتكنولوجيا المعلومات: يعرف عبد الهادي مجتمع المعرفة على أنه المجتمع التي ينشغل معظم أفراده بإنتاج بإنتاج المعلومات أو جمعها أو اختزانها أو توزيعها, ويتخدمها كوجه للحياء الاقتصادية 


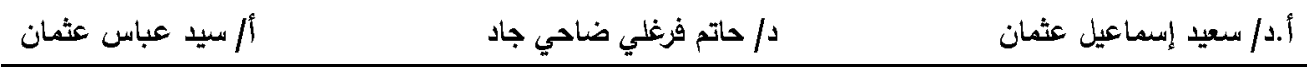

الاقتصـادية والاجتماعيـة والثقافيـة و السياسية، ويعتمد عليها اعتمـادا أساسـيا كمـورد

استثماري وسلعة إستراتيجية وخدمة ومصدر للاخل القومي ومجال للقوي العاملة. (عبد

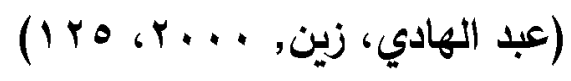

فهو مجتمع الثورة الرقمية التي أسهت فى تغيير العلاقات فى المجتمعات المتطورة حيث أ صبحت المعلومة والمعرفة سمة ومقياس لمعنى القوة والتفوق فى صياغة أنماط الحياة، وضاعفت من سرعة التراكم المعرفي. (خليفة، محم، V + +. Y، I I)

فهو المجتمع الني يستطيع كل فرد فيه استحداث المعلومات والمعارف، والنفاذ إليها، واستخدامها، وتقاسمها، بحيث يمكن الأفراد والمجتمعات من تسخير كامل إمكاناتهم في النهوض بتنميتهم المستدامة، وفي تحسين نوعية حياتهم، ويعتمد على إطلاق الحريات والرئي والتعبير والتظيم، والثر الكامل للتعليم الجيد، وتوطين العلم، والتحول نحو إنتاج المعرفة في البيئة الاجتماعية والاقتصـادية. (ضــاوي، بيـومي، والمليجي، رضـا، $(1 \wedge, r \cdot 1+$

وتصحمن عرض التعريفات الهابقة أن هناك نقط اتفاق كثيرة حول مفهوم "مجتمع المعرفة" تكمن في النقاط التالية: ـ مجتمـع المعرفة هو المجتمع الذي يهتم بدورة المعرفة وعملياتها من توليـ للمعرفة ونشرها وتوظيفها. • مجتمع المعرفة يهتم بتوظيف المعرفة واستخدامها في عملية التنمية. - المعـارف والمعلومـات تتدفق بسهولة ويسـر في مجتمـع المعرفـة بدون عقبـات أو صعوبات، بيث يمكن الوصول إليها بطريقة سريعة، وبوسائل متعددة، وتكلفة رخيصة. 


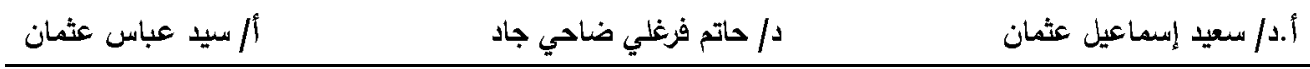

- مجتمع المعرفة يسهم بفاعلية في إنتاج المعرفة وتطويرها، ولا يكتفي بمجرد إتقان الاستفادة منها، وحسن استعمالها وتوظيفها لتحقيق التنمية المنشودة للجميع. - في مجتمع المعرفة، تؤدي المعرفة دورا هاما وأساسيا في التنمية البثرية. - ميعتمد مجتمع المعرفة بشكل أساسي على الإبداع الفكري والإنتاج المعرفي في صورة تتجاوز الحدود المكانية والزمانية.

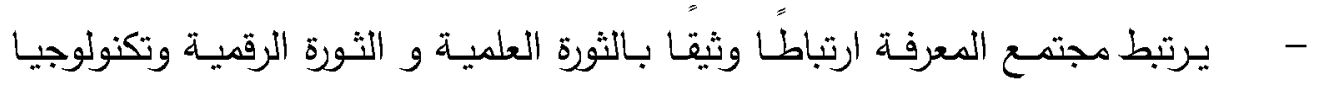
المعلومات والاتصالات. - م.ت.

• برز مجتمع المعرفة كنتيجةطبيعية للنطور الاقتصادي والتكنولوجي الأي شهده التاريخ الإنساني. و بناء على ما سبق يعرف الجث الحالي مجتمع المعرفة على أنه المجتمع الذي لديه القدرة على توليد المعرفة وتقاسمها وحسن توظيفها، والاستفادة من آليات التكنولوجيا الحديثة لتحقيق التنمية الثاملة في كل المجالات. r ـ مراحل تطور مجتمع المعرفة

إن فكرة مجتمع المعرفة ليت بالأمر الجديد، بل الجديد هو حجم تأثير المعرفة الراهن على الحياة الإمادية والاجتماعية والتقافية، وعلى نهط حياة الإشسان المعاصر عموما. فقكرة مجتمع المعرفة تدور في إطار زمني يسل إلي نصف قرن, لكنها لم تتبلور كما هي اليوم. - n

وتؤكد الأدبيات على أن العالم قد شهر منذ مضف القرن العشرين أعظم تغيير في في تاريخ البشرية، وهذا التغيير يأتي بعد مراحل تطور عديدة، بدأت بالمجتمع الزراعي الزراعي الفى امتد آلاف للنين وحتى مقف القرن الثامن عثر، هث بدأ التحول نحوعر نحو عر جديد وهو المجتمع الصناعي الذى استبدل الحقل بالمصنع، واستبدل صاحب صلب الأرضبلب رأس الـ مال، واستمر هذا الصر حتى مضف القرن الثشرين، إذظهر 


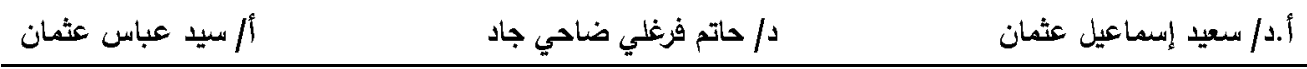

الشرين، إذظهر عهر آخر هو الصر المعلوماتي الذي يعتمد على المعلومات (تكنولوجيا (تكنولوجيا المعلومات)، إذ تحك القيادة من الآلة إلى النظم الإلكترونية التى تتحكم بالآلة بالآتة والمصنع وبكل مجالات الحياة التى يديرها من يمتلك الذكاء وأدوات تكنولوجيا المعلومات، وهم القادرون على السيطرة على الأجهزة الإلكترونيـة والبرمجـة والأنظمـة

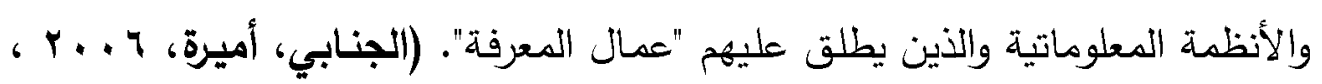

وقد حدثت تحولات كبرى فى العالم وتحديدا فى الاول الغربية بغحل تنامي دور

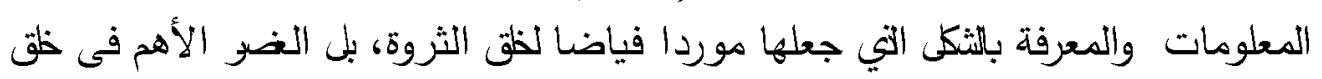
الأهم فى خلق القيمة. ومـا يؤكد التنامي السريع في دور المعرفة كمورد إستراتيجي لمنظمات القرن لحلي والعشرين هو التحول الجذري فى تركيبة القدرات والموارد البشرية. البشرية. فقد لُوحظتنظا كبيرا فى أعداد العاملين فى قطاع الزراعة والصناعة مع دخول دخول مجتمعات عصر المعلومات، مما صـاحبه ارتفاع واضـح فى أعداد العاملين فى قطاع المطومات أو ما يطلق عليهم بعمال المعرفة أو ذوي الياقات البيضاء الذين يتولون يتولون إنتاج القيمة الاقتصـادية للمجتمع من خلال استخدام المعلومات والمعرفة، وهم المهندسون والمعمـاريون والعلمـاء، وهؤلاء أصبحوا أكبر قوة عاملة ذات أهميـة كبيرة لمنظماتهم، وأصبح العمل المعرفي يشكل • ؟\% من الناتج المحلي للولايات المتحدة الأمريكية، والقوى العاملة شثكل حوالى ه\% من حجم القوة العاملة الكلية. \&audan \&

\section{(Laudan \& Laudan, 2000, 25-26)}

ولقد كانت صناعة المعرفة قي العصر الزراعي ترفًا لا يمارسها إلا الأغنياء، ولا ولا شثعها غير السلاطين والحكام ولا يستخدها غير أصحاب النفوذ السياسي والهيمنة والهيمنة الاجتماعية والثقافية، أما في الصر للمناعي فإن المعرفة أصبحت وسيلة لتقدم لتقدم الإساد وتطور التكنولوجيا وتحرر الفرد والمجتمع، وهذا جعها تتحول من مبادرات 


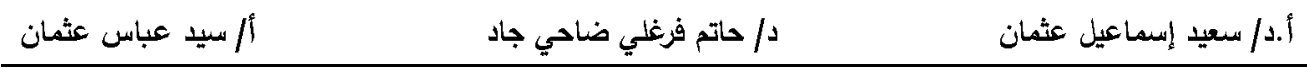

مبادرات فرديـة إلى عمليات مؤسسية تملكها الدولتة وأصـاب المصـالح الاقتصـادية، ويستخدمها الحكام ورجـال الأعمال وأصـحاب رؤوس الأموال لزيـادة ثرواتهم وتكريس وتكيّ نفوذهم، وفي هرر العولمة أصبحت المعرفة حاجة فردية ومجتمعية ماسة، وأهم وأهم أدوات تحرير الذات من كل القيود الاجتماعية والسياسية والاقتصادية، بما في ذلك ثلك قيود الفقر والكبت السياسي والاجتماعي والتبعية الفكرية وغير الفكرية. (ربيع، محهد،

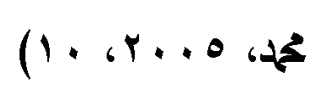

ولقد أُستخدمصطلح مجتمع المعرفة لأول مرة عام ب7 19 أهي مقالة للمتخصص في العلوم السياسية روبريت لين Robert Lane الذي طالب باستبدال السياسات غير المنطقية بمعرفة أكثر منطقية تستعمل في تحسين عمية صناعة لقرارات ذات الأبعاد

(Kring, Bettina, 2006, 10) الاجتماعية. ويرى يـول هوير Paul Hopper في كتابه (نحو فهم للعولمـة الثقافيـة) أن مجتمع المعرفة قد مرَّ بثَلاث موجات حتى تشَكَل بصورته الحالية، وهي (هوبِر، يول، $:(r+-1 V, r+1)$

1 - الموجة الأولى: يرى أنها تتمثل في الاقتصاد العالمي والأسواق المفتوحة، وانهيار الحـدود القوميـة وعولمـة الاقتصـاد والتجــارة، وحركـة رأس المـال والمعلومـات والبشـر والاستثمار العالمي، والمؤسسات متعددة الجنسيات، والمتضمنات الثقافية. وتمثل هذه التطورات، في رأيه، تحديات كبرى للدولة- الأمسة؛ إذ إنها تسهم في تقييد استقلالية الحكومات في إدارة سياستها واقتصادها. Y - الموجـة الثانيـة: وهـي مرحلة الاقتراب من العولمـة التي تقودهـا الرأسمالية، وهـي مرحلة جدل سياسي وفكي تذب فيه بعض الأصوات إلى أن النظام العالمي مستمر في في خضوعه لاول تمتلك قدرات اقتصـادية وعسكربة كبرى، أبرزها الولايات المتحدة الأمريكية، فالتجارة والاستتمار والتدفقات الماليـة مركزة في ثـلاث بيئات فقط، هي: 


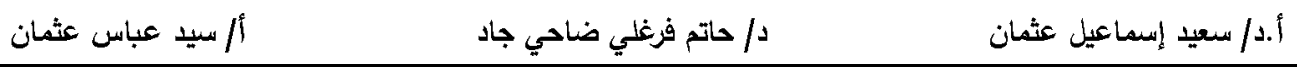

أوروبا، واليابان، وأمريكا الثمالية؛ لذا فإن وصف هذه المرحلة بمرحلة التثليث (أوروبا، (أوروبا، اليابان، أمريكا) أصوب من وصفها بالعولمة. r - الموجة الثالثة: وهي وف للثطور غير المسبوق في التدفقات الإتصادية والثقافية، ومستويات أعلى في التواصل الكوني الناتج عن قوى الحداثة مجتمعة، وهذه الموجة تمثل مرحلة (العولمة) التي هي عملية تحويلية قويـة ومعقدة وغير نهائية، وهي مسئولة عن

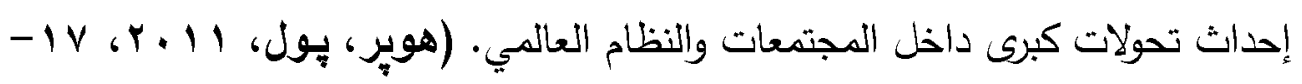

وخلاصة القول، إن مجتمع المعرفة يجد أحدث أشكال تطور المجتمع الإنساني، الذي مر بعدة نظورات بدايةً بظهور المجتمع الزراعي، ومرورا بالمجتمع الصناعي، ثم مجتمع

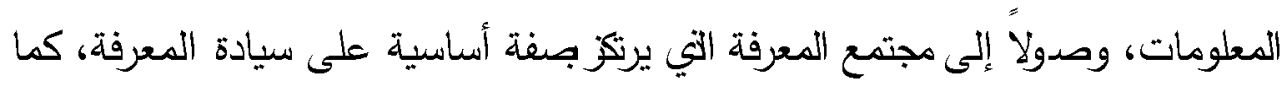
يعتمد على إنتاج المعرفة وتوظيفها في كل الأنشطة الحياتية، وعلي رأسها الاقتصـاد المعرفي، الذي يرفع قيمة المعرفة وأهميتها في كافة أوجه الحياة.

\section{r ـ خصائص مجتمع المعرفة}

يتميز مجتمع المعرفة بجموعة من السمات والصفات التي تتاولها الكثير من الكتَّاب الكتًاب والباحثين والمفكرين، فلقد وصف اتوفلره التغيرات الكبيرة في البيئة المعاصرة المعاصرة لمجتمع المعرفة، والتي صاغت وضعا جديدا شهده المجتمع الأمريكي، وهيي وهي حالة اقتصادية واجتماعية تجاوزت المجتمع الصناعي (الموجة الثانية)، الذي كان كان يعتمد على الصنع، والذي بدأ دوره يضمحل، باعتباره آلية توحيد قياسي يقوم على على التنميط والمركزية والزيادة المفرطة والروتينية. فقد تجاوزت الحضارة الأمريكية، في 


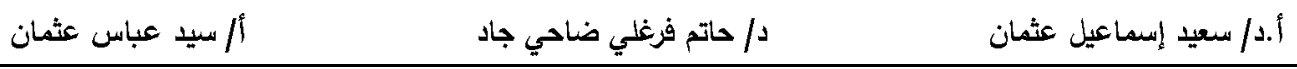

الأمريكية، في رأي توفلر، هذا النمط إلى مجتمع المعرفة (مجتمع الموجة الثالثة) الذي الذي تتمثل خصائصه في الآتي(توفلر، ألفن، 999 19، ه ـ 1-11 11): - الاستناد على مبلى الصادية جديدة، ويحدث في أمكن جديدة لا تكاد تشبه المصنع؛

$$
\text { وكثير من إنتاجه يتم في المنازل والمكاتب والسيارات والطائرات. }
$$

- شجيع نوعية من العمالةتخف اهـاديا عن عمالة المجتمع الصناعي؛ فهي عمالة تفكر وتطرح الأسئلة وتبتكر ، وتخاطر مخاطرة صاحب العمل.

- الاعتماد على القوة الذهنية التي تؤي إلى التذوع في المجتمع، فالإنتاج الكومبيوتري

$$
\text { جعل تنويع أساليب الحياء أمرا يسيرا. }
$$

- تؤدي كثافة الإعلام دورا مركزيا فيه؛ إذ يعمل الإعلام على تفكيك الكتل الكبيرة في ميادين الثقافة والقيم والأخلاق. - استحداث أشكالاً جديدة لشغل أوقات الفراغ، وابتكار أساليب فنية جديدة. - التذوع الاجتماعي، وهو تنوع ينسف التنيمات شديدة المركزية. - سيادة القطاع الخاص، حيث يعول كثيرا على القطاع الخاص في البعد الاقتصادي، ويتحرك بسرعة فائقة.

- إعادة دور الأسرة؛ حيث تأتي الموجة الثالثة لتع يـ للأسرة والمنزل مهمات ونفوذا؛ إنها تعيد كثيرا من الفظف المفقودة التي تجعل للمنزل مكانة مركزية في المجتمع؛ حيث يمكن للأفراد القيام بجزء من عمهم في المنزل؛ مستخدمين الكومبيوترات أو الفاكسات، أو غيرها من وسائل التكنولوجيا الحديثة.

(Slaus, I., ، (Britz, J. et al, 2006, 25-40) ومن سمات مجتمع المعرفة ليذنا

:2007, 986-996)

إنـه يعمل على تحديـد المعلومـات والمعرفـة وإنتاجهـا، وتحويلهـا، ونشـرها، واستخدامها من أجل التنمية البشرية. 


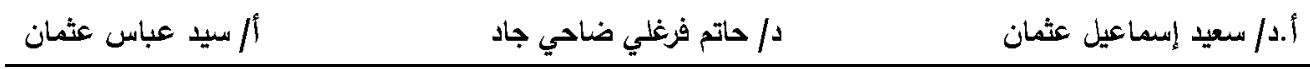

إنـه يستفيد ويهيئ الطرق الضرورية لجعل العولمـة تخدم البثرية وتساعد في

رخائها.

إنه دائم التطور والتغير نحو الهنلى، ولديه من أجل تحقيق ذلك رؤية عالمية طويلة

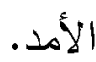

إن المعرفة هي المصدر الرئيس لقوته السياسية. الطاقة البشرية قيمة مميزة فيه؛ وذلك بجعل البشر هم المصدر الرئيسي للإنتاج

$$
\text { والإبداع. }
$$

إنه متواصل ومترابط بشكل جيد ومتين عبر وسائل الاتصال والتواصل الحديث،

$$
\text { ويمكنه أن يصل إلى مصادر المعلومات بسهولة ويسر · }
$$

إنه يعمل تحت مظلة اقتصاد المعلومات.

لـى مجتمع المعرفـة البنيـة التحتيـة الماديـة المتينـة التي يقوم عليهـا أساسـه الإمسادي المتين، والتي توفر الدعم المادي لتقل المعلومات والعلوم وتوصيلها.

ويتميز مجتمع المعرفة بانتشار استخدام المعلومات بين أفراد المجتمع بكل فئاته، مع إمكانية تقديم التنهيلات والخدمات المعلوماتية لكل أبناء المجتمع ومؤسساته، من خلال شبكة المعلومات العالمية، بالإضافة إلى استخدامها كمورد الصادي من خلال الاستفادة من رفع كفاهة المنظمات والهيئات والمؤسسات المختلفة، هذا إلى جانب تشجيع الابتكار والإبـداع وتتميـة القدرة التنافسية لنـاتج المؤسسـات الاقتصـادية والمؤسسـات الخدميـة

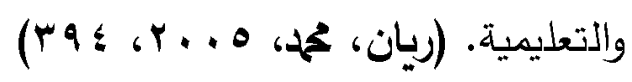

كما يبرز في مجتمع المعرفة مفهوم العولمة، الذي يفترض أن يحقق "توسيع وتعميق وتعميق وتسريع الترابط في جميع أنحاء العالم". وفي مجتمع المعرفة تزداد أهمية مؤسسات مؤسسات التعليم العالي أكثر من في وقت مضى، حيث إنها تعد بمثابة وسائط في اقتصاد 


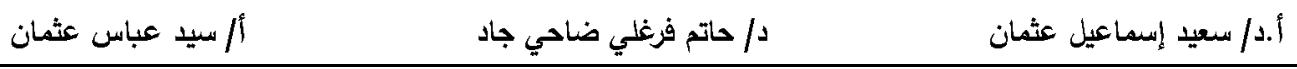

التصاد المعرفة العالمي؛ إذ أنها جزه لا يتجزأ من التدفقات المستمرة من البشر ، والمعرفة، والمعرفة، والمعلومات، والتكنولوجيا والمنتجات ورأس المال. Välimaa, Jussi ) \& Hoffman, David, 2008, 266) وهنايك سمات أخى تمن تطوير مجتمع المعرفة للطريقة التي يتميز بها الإنتاج،

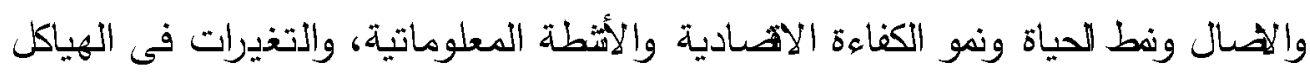
المهنية، والتحول نحو المهين التخصصية، وشبكات المعلومات، والتغيرات التي تحدث فى التظيم الزماني والمكاني الحياة الاجتماعية، بالإضافة إلى إنتاج وانتثار الصور الثقافية والحضارية فى كل أرجاء العالم. (Webster, Frank, 2002, 8- 12).

ويؤكد مجتمـع المعرفـة على التحول إلى قوة العمل ذو المهارات العالية للمعرفة الكثيفة، وانتشـار العقول الدوليـة، والتعلم مدى الحيـاة، والمهـارات والكفايـات القابلــة للتحويل، وإدارة المعرفة كقدرة مؤسسية وفردية (Nokkala, Terhi, 2007, 71).

$$
\text { ومن خصائص مجتمع المعرفة (علي، عبل العليم، ب I + r، بrه): }
$$

1 - رأس المال المعرفي؛ امتلاك كفايات معرفية في شتى المجالات، وامتلاك قدرات ذهذية خلاقة. r - استخدام التكنولوجيا الحديثة في تجاوز الإطار الزمني المكاني. r - توليد المعرفة وتقاسمها وحفظها واستعادتها، واعتبار المعرفة وتطبيقاتها المحك الحقيقي. ع - الابتكار ؛ يتميز مجتمع المعرفة بالقدر الابتكارية؛ فهو مجتمع ينتج المعرفة. 


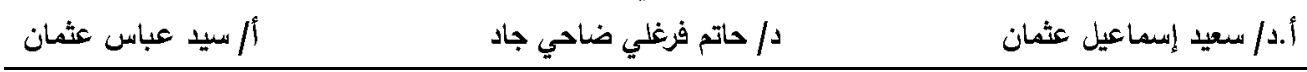

ه - جودة التعليم؛ يتميز مجتمع المعرفة بأن التعليم هو الركيزة الأساسية في التخطيط الاستراتيجي؛ وهذا ما أخل اليابان في مجتمع المعرفة. ويخح تطور اليابان السريع في كونها رصدت للتعليم بع \% من ميزانيات المدن والقرى. 7 - امتلاك القدرة التظيمية التي تعلى على إنتاج المعرفة ونشرها؛ وذلك بسن القوانين المنظمة للعلاقات والأس الإدارية؛ للابتعاد من التقديرات الثخصية التي تتأثر بمجموعة معطيات نفية وتأثيرات أيديولوجية وغيرها. ويمكن إيجاز خصائص مجتمع المعرفة في سمة رئيسة، وهي إتاحة المعلومات والاستفادة منها، بمعنى أن ما يميز مجتمع المعرفة ليس وجود المعرفة فقط، وإنما طرق وأساليب إتاحة هذه المعلومات، وتيسير الوصول إليها، وتفعيل الطرق والأساليب العلمية للاستفادة من هذه المعلومات في أوجه الحياة المختلفة، وفي حل مشاكل المجتمعات، وتنميتها، وتحقق التكيف المطلوب مع التغيرات التى أفرزتها ثورة المعلومات. (الحربي،

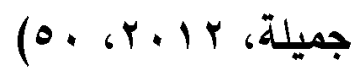
ومن خلال ما سبق يمكن القول بأن أن سيطرة المعرفة هي السمة الأهم والأبرز لمجتمع المعرفة؛ فقد نتج عنها التحول نحو اقتصاد المعرفة، وفي هذا السياق ظهرت عدة مصطلحات أبرزهـا: "إدارة المعرفـة"، و "رأس المـال المعرفي" و "المهـن كثيفة المعرفـة"، و "عمال المعرفة"، و"الاقتصاد الرقمي"، و "المعرفة الإنتاجية". كما أن مما يميز مجتمع المعرفة حسن توظيف وسائل التكنولوجيا الحديثة، والاستفادة مما أحدثته ثورة المعلومات

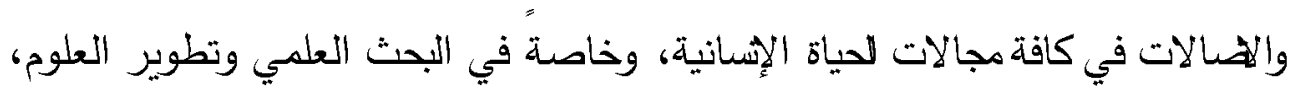
والاهتمـام بالتعليم والتدريب، والإعـلام والترجمـة، والنثـر العلمي، والعمل على تأهيل الكوادر البشرية القادرة على إنتاج المعرفة وحسن توظيفها في ميادين الحياء البشرية 


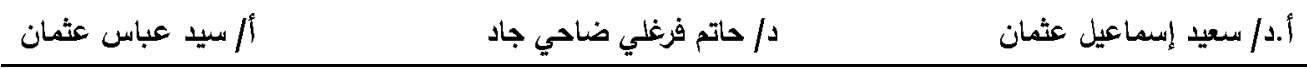

\section{؛ - متطلبات بناء مجتمع المعرفة}

بالرغم من تعدد منطلبات التحول إلى مجتمع المعرفة، يظل الضر البشي هو العنصر الأسـاس في مجتمع المعرفة، أما التكنولوجيا فهي الأداة المساعدة ضمن هزا السياق، ويـعم هذه الفكرة نبيل على بقولهه بأن صناعة مجتمع المعرفة قوامها آلات مزودة بآليات، تستخدم هذه الآلات كأدوات لتوليد منتجاتها، ويرى أن الآلات هي العقول، متمثلة في ثلاثية من العقول: العقل الإنساني والعقل الآلي والعقل الجمعي، وآلياتها هي وسائل التفكير، وقد درج علماء النفس أنواع التفكير تحت طورين أساسيين، هما التفكير

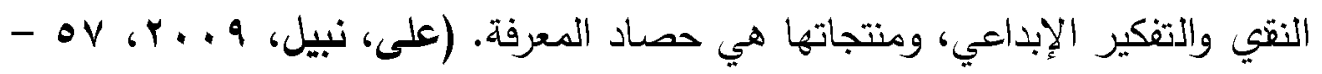

وقد أثار تقرير التنمية الإنسانية العربية ب + . r إلى إن بناء مجتمع المعرفة في المجتمع العربي، يستند على خمس مقومات تعد بمثابة متطلبات أساسية هي: (البرنامج

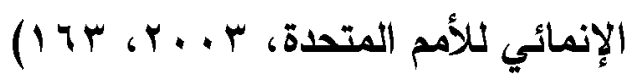
- إطلاق حريات الرأي، والتعبير، والتظيم، وضمانها بالحكم الرشيد. - انتشار التعليم راقي النوعية، من خلا الاهتمام بإصلاح التعليم. - توطين العلم وبناء قدرة ذاتية في البحث، والتطوير التكنولوجي في جميع الأنثطة المجتمعية. - التحول نحو نمط إنتاج المعرفة على مستوى البنية الاجتماعية والاقتصادية. - تأسيس نموذج معرفي عربي عام وأصيل، منفتح ومستنير • ومن أهم متطلبات بناء مجتمع المعرفة في: إقرار استراتيجيات وطنية متماسكة، وبنـاء سياسـة لتكنولوجيـا المعلومـات، بالإضـافة إلى بنـاء بيئـة للاستتمار ، وتطـوير شبكات المعلومات لضمان إتاحة كل أنواع تكنولوجيا المعلومات، وقيام القطاع العام باستخدام فعـال لتكنولوجيا المعلومـات، وتشـيع توزيـع خدمات مباشـرة عبر الشبكة، 


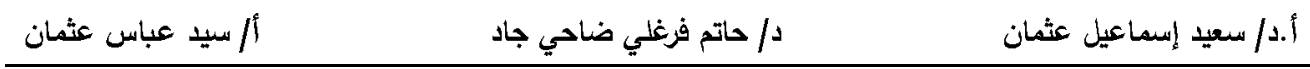

ووصول جميع المواطنين إلي المعلومات والخدمات الحكومية، علاوة على تطوير الموارد الموارد البثرية، عبر تبني ثقافة تكنولوجيا المعلومـات ومهاراتها عبر التعليم والتعلم والتد ريب من الحياة من إنثاء مدارس وصفوف ومكتبات مباشرة على الثبكة، وتدريس وتدريس مهارات تكنولوجيا المعلومات والنظم المتعددة الوسائط. (محي الدين، حسانة،

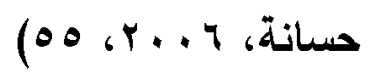
ويبين لورد Lord أن تحقيق مجتمع المعرفة بحاجة إلى توفير المتطلبات التالية

:(Lord, K., 2008, 12) المناخ الأعم لحرية التعبير وممارسة الإبداع. التعليم عال الجودة في كل المستويات والمراحل التعليمية. اهتمام كبير وعناية فائقة في مجال العلوم والبحوث العلمية. قطاع صناعي قائم على إنتاج المعرفة. ثقافة التعليم والإبداع.

ويلس الصاوي متطلبات بناء مجتمع المعرفة في المحاور التالية (الصاوي، ياسر،

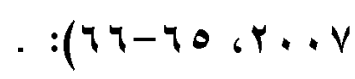

- الاستعداد الرقمي والني يعني لِلال خدمة الضصالات لجميع الأطراف في جميع أنحاء النظام المؤسسي. - الإدارة الإلكترونية والتي تهدف للعمل علي تقديم الخدمات لجميع العاملين في مكان تواجدهم, بالسرعة والكفاءة المطلوبة. - الأعمال الإكترونيـة التي تهدف إلي بنـاء مجتمع رقمي لا ورقي, والعمل في هذا المحور يـتم علي عدة مراحل تشمل البنيـة الأساسية ثم البيئة التشربعية ثم البيئة التتظيمية لتطبيقات الأعمال الإكترونية، وأخيرا العطل علي التوعية بأهمية هذه الأعمال

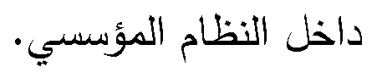




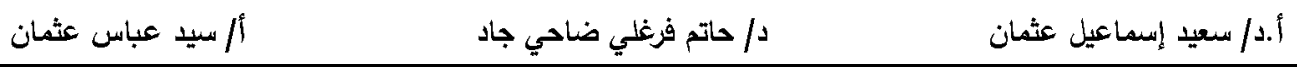

- التعليم الإكتروني لرفع القدرات التنافسية لقوة العمل المؤسسية, باستخدام النظم الإكترونية التفاعلية الحديثة عبر شبكات المعلومات.

- تنميـة صـناعة تكنولوجيا الاتصـالات والمعلومـات بهدف تعميم خدمات تكنولوجيا المعلومات والإلالات بالمؤسسة, وجذب الشركات العالمية لتوطين المعرفة والتكنولوجيا.

وبصفة عامة يمكن ملاحظة أن معظم متطلبات بناء مجتمع المعرفة تتركز حول

التعليم، مما يـل على أهميـة الاستثمار فى مجال التعليم. حيث تتوقف الانطلاقة الآصادية على إمكانية تحقيق استثمار كيق فى البشر من خلال التعليم. حيث أصبحت تقاس درجة ا لتقدم بالفارق بين مدى اكتساب المعرفة وفى القدرة على اكتسابها. ومن المعلوم أن هناك ثلاث طرق لاكتساب المعرفة وهى التعليم والبحث العلمي والتطوير

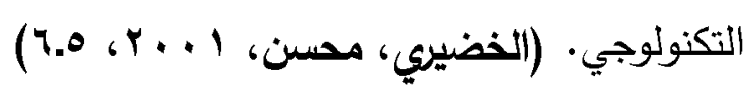

ومن خلال استعراض متطلبات بناء مجتمع المعرفة السابقة, يمكن تحديد بعض أهم المحاور الرئيسة في بناء مجتمع المعرفة في جمهورية مصر العربية, وهي:. - الاهتمام بتمية رأس المال البثري من خلال تطوير وتحسين نوعية التعليم والتدريب، والتركيز على إكساب المتعلمين والمواطنين المهارات اللزمـة لاكتساب ونشر وإنتاج المعرفة. - العمل على زيادة الميزانية المخصصة للتعليم والبحث العلمي. - تشييد بنية تحتية فعالة لتكنولوجيا المعلومات، تسهم في نشر تكنولوجيا المعلومات والاتصالات في كل أنحاء مصر · - إصدار تشريعات تكفل الوصول الشامل للمعلومات والمعرفة. • - التحول التربوي نحو مجتمع المعرفة 


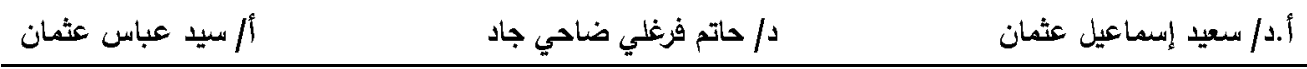

يعد التعليم بمثابة بوابة مجتمع المعرفة، هث تسعى فيه الدول إلى إجراء تعديلات جذرية في أنظمتها التعليمية الوطنية، وذلك على مستوى المضمون والآليات والوسائل

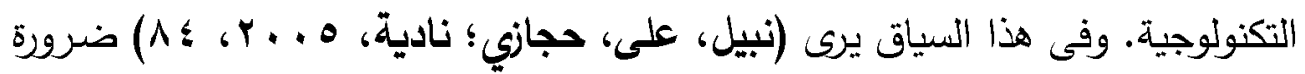
استهداف تكنولوجيا الضالات والمعلومات، وإدماجها في برامج التعليم، وتحديد المنلب منها في ضوه احتياجات المجتمع المستقبلية ومتطلبات تأهيل وتثثيف أفراده.

و لا يمكن أن يتهق التغير المثشود لتوجيه المجتمع نحو مجتمع المعرفة دون مساهمة فعالة من القادة التربويين القائمين على بناء وإدارة عمليات التعلم في ميدانه العملي، ذلك يستدعي التخلي عن الاستراتجيات التقليدية، والتي نتائجها لم تتجاوز كثيرا حدود

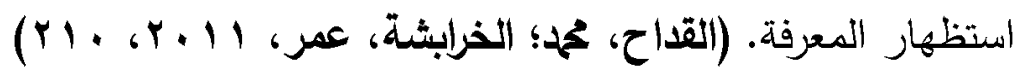
ويواجـه التعليم عدة تحديات في مجتمع المعرفة، أهمها: القدرة على استكثـاف الطرق الجديدة للتعليم، واستتباط حلول تستند إلى معرفة ممتازة للوسـائل التكنولوجية والوسائط الحديثة المستخدمة في التعليم، وكيفية تصميم بيئة التعليم التفاعلي، مع فهم لنقاط الضعف والقوة في التطبيقات التكنولوجية الحديثة، وإعادة الاكتشاف والإبداع في استخدام واستثمار الوسلط التكنولوجية في توسيع نطاق التعليم في المجتمعات الحديثة، وبالتالي توسيع التدريب. وتبقى قيمـة التكنولوجيا في التعليم في القدرة على الوصول إلى عدد غير محدد، ورفع مستوى التعليم ونوعيته، وتطبيق سياسـة التعليم المستمر •

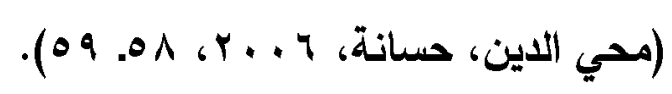

ومن متطلبات التحول التربوي نحو مجتمـع المعرفة تطوير النظم التربويـة لتلبى احتياجات المتعلم والتمية الاقتصادية والاجتماعية، والسعي إلى تكوين الإنسان متعدد المهارات، والعمل بمبدأ التربية المستدامة ومساعدة المدرسة لإعداد الإنسان القادر على إلى

$$
\text { التعلم الذاتي. (علي، نبيل، ؛ . . ب، ؛ ؛ ) }
$$




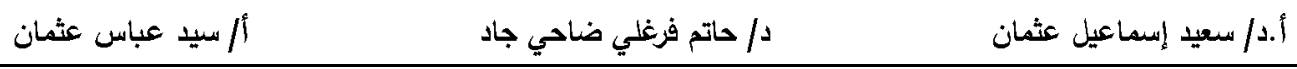

ومجتمع المعرفة يتطب من النظام التعليمي، "اعتماد فلسفة تربوية تساعد على اكساب المتعلمين القدرات والمهارات التي تمكنهم من تفير الظواهز وضل الحقائق، والتأكيد على التحول نحو تنمية قدرات المتعلم، وتطوير الإنسان المنتج للمعرفة المبدع للتكنولوجيا مع وحدة المعرفة وتقارب العلوم وتكاملها، بالإضافة إلى تنيم الاستفادة مما يوفره التطوير التكنولوجي من أدوات تعليمية إلكترونية عديدة من أهمها مواجهة الطلب المتزايد على

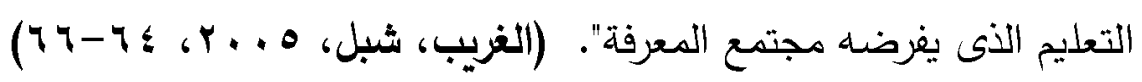

وفي هذا السياق، ينبغي على التربيـة أن تسعى لإكسـاب ألوان مـن المهارات

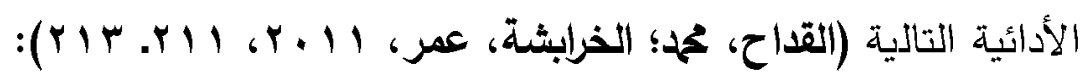
ـ المهارات الأساسية للتعلم مثل البث في مادر المعلومات وتنظيم المعرفة، ومهارات التواصل واستخدام الحاسب الآلي والانترنت، وتحليل البيانات. ـ المهارات التصية: كالتقييم، والتحليل العلمي، وتشيض المشكلات، وإجراء التطبيقات العملية في توظيف الجوانب النظرية. ـ المهارات الميتامعرفية: وترتبط بتفعيل المعمل الاماغي لاى المتعلم، كالتنظيم الذهني في طرح الأفكار ، وحل المشكلات، والاستدلال، وسرعة المفاضلة بين البدائل والحلول. ـ المهارات الاجتماعية: وتعني القدرة على التعامل هع الأشخاص، والمواقف من حيث استقطاب الآخرين، وتفهم مشكلاتهم، وكسب ودهم. وقد لا يتو الفرد عند شك، بل يرتقي إلى مرحلة تطوير المعرفة وإنتاجها، ويحقق شروط المنافسة العلمية، وعندئذ سيساهمون بدرجة كبيرة في تثكيل منظومة القيم التي تتأثر بالتجد المعرفي لبني الإنسان. 


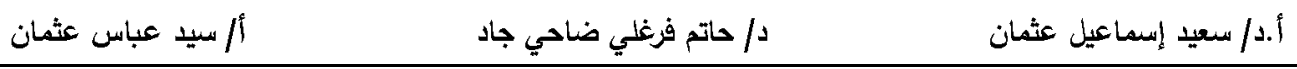

وفي مجتمع المعرفة ينبني العمل على اكساب المعلمين والمتعلمين مهارات إنتاج المعرفة ليتمكنوا من التعلث مع تحدياتها، والتحول من التعلم من أجل المعرفة إلى التعلم هن أجل العمل ومن التعلم من التعايث مع الآخرين إلى التعلم من أجل أن نكون. وهكذا

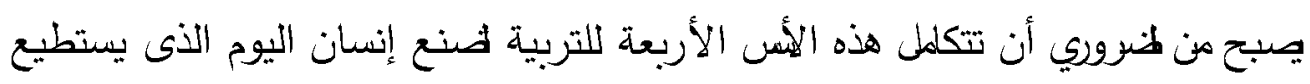
أن يتكيف ويتعايش مع عالم الغد، ومن الـ مهم للإنسان أن يتعلم ليكون صانعا للمعرفة وهدَّرا لها، ولي مجرد مستهلك أو أن يكون ما يريد هو أن يكون لنفسه في إطار من

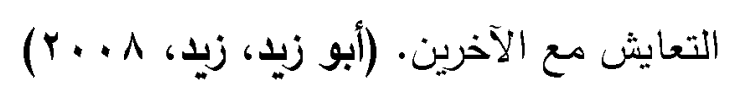

والتحول التربوي نمو مجتمع المعرفة يتطب بناء منظومة بث وتطوير وعلم وتكنولوجيا للإبـداع والابتكار فاعلة، ويتمثل هدف هذه المنظومـة في رفع المستوى الاقتصـادي والمعرفي في آن واحد. وتتكون هذه المنظومة من عدة عناصر هامة وضرورية ومكملة لبضها البن، فالهث والتطوير يتطلب تعليما مستمرا، ويحتاج إلى جهاز للتيقيم المستمر، يتكون من كادر عال المهارة، يجب أن تتوفر له معلومات بقدر كبير خاصة في الأمور والإجراءات التي تكفل نجاح منظومة البحث والتطوير • (مرياتي، تحم، د.ت.)

ولقد عرض أحد الباحثين تصورا لمجموعة من المتطلبات التربويـة التي تدعم بناء

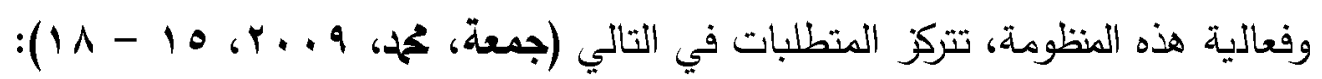

- تعزيز قدرة الطالب على الحصول على المعرفة وتوظيفها؛ بما يعني ضرورة تحويل التعليم من أداة لنقل المعارف إلى أدلة لتعليم الطالب كيفية التعلم.

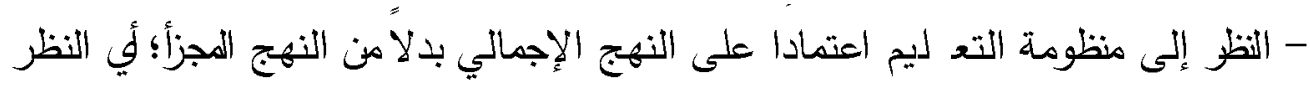
إلى جميع مراحل التعليم بشكل شامل ومتكامل، بالاعتماد على منهج التظطيط الاستراتيجي في العملية التعليمية تحقيقا للترابط بين كل من الأهداف والسياسات. 


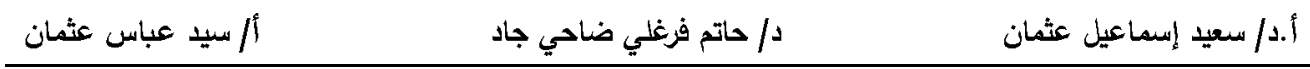

- تعزيز العلى لجماعي سواء على مستوى المنظومات الفرعية لمنظومة التعليم أو على مستوى إدارة هذه المنظمات فيما بينها. - الاستخدام الفعال لتكنولوجيا المعلومات؛ نظرا لما لهامن أهمية كبيرة علي مستوى للب والمعلم والإدارة والعملية التعليمية، ويرتبط ذلك بضرورة التوسع في نشر التعليم عن بعد لما له من فوائد كبيرة في التعليم المستمر - لمن - التوسع في مفهوم المدرسة الذكية التي تدعم بقوة منطلبات نطوير التعليم جفة عامة، مما يساهم في تخريج كوادر قادرة على التعامل مـع التكنولوجيا الحديثة بكافة أشكالها، وهذا بـدوره يـؤدي إلى انتقال التعليم إلى مرهلـة اكتسـاب الأجيـال الناشـئة مهارات التعليم الواعي والمستمر والإبداع والابتكار • - التوسع في مفهوم جامعة العتقبل، والتي تستخدم مخرجات المدرسة الاكية كمخخلات لها، بما يعني استكمالها لف الأهداف وقيامها على خطوات مشابهة لخطوات المدرسة الأكية مع بعض الاختلافات.

- الإنفاق المتزايـ على التعليم؛ بمـا يـنعس على نوعيـة التعليم خاصــة فيمـا يتعلق بالتكنولوجيا المتقدمة، من خلال توفير أجهزة الكمبيوتز في المدارس، والاستغلال اله؛ لها، حتى يتحقق الهدف المنشود من وراء هذا الإنفاق. - إصـلاح الخلل في نسبة الملتحقين بفروع العلوم والرياضيات مقارنـة بفروع العلوم الإنانية والاجتماعية، حيث أن نسبة الملتحقين بفروع العلوم والرياضيات بالعالم العربي نحو rr\% فقط، ويعد هذا الأمر من أهم تحديات الدخول إلى مجتمع المعرفة.

- تكوين المؤسسات ذات القدرة على استيعاب فكر ومتطلبات مجتمع المعرفة، ونشر تعليمه، والاستفادة من إنجازاتـه وابتكاراته؛ ممـا يساعد في مواجهة التحديات المعوقة لفاعلية منظومة التعليم. 


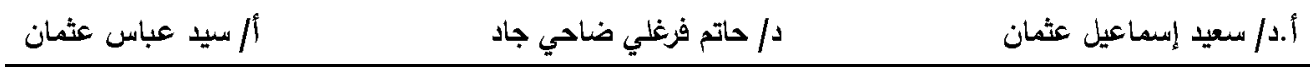

- توسيع الهثاركة المجتمعية من خلا التوجه نحو اللامركزية لما لها من ايجابيات في إدارة منظومة التعليم، لمواجهة التحديات الاخلية والخارجية للمنظومة. - اسـتكمال البنيـة الأساسية للمعرفـة مـن خـلال تعليم فني متطـور وجذاب للثباب، والاستفادة القصوى من الطاقة التعليمية في مرحلة الطفولة المبكرة، وإيقاف التسرب من التعليم، وتخفيض معدلات الأمية بكافة أشكالها.

ويتطب التحول التربي نحو مجتمع المعرفة في الوطن العربي ما يلي: (توفيق، صلاح

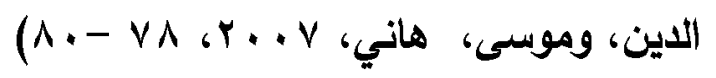

ـ عقد مؤتمرات استثنائية للمسئولين من الوزراء العرب والوزراء المختصين والمهتمين بالتربية والتعليم في الوطن العربي، لتعزيز تبادل الأفكار والخبرات والتجارب والمساهمة في تطوير التعليم العربي، وتوسيع قاعدته وفق المعايير والضوابط العالمية.

ـ تتفيذ مشـروعات عربية موحدة، والعمل على توسيع نطـاق استخدامها وزيـادة عدد

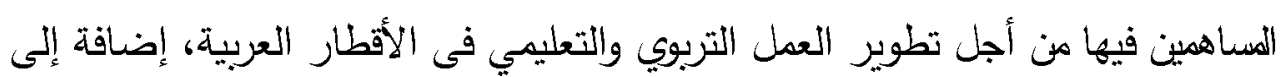
بناء أسس الوحدة التعليمية التكاملية. ـ استثمار الإمكانات المادية المتاحة في تعزيز الحركة العلمية، وتوفير عناصر الجذب المتنوعة والمهمة من احترام البحث العلمي وإنتاجه والتي منها الأجور المرتفعة والتألق العلمي والاجتماعي والمالي للمعلم في جميع المراحل التعليمية، كوسيلة تمكنه من إنجاز الطموح العل مي الذي يتوق إليه، وتقدير العلم والعلماء، وتقدير الابتكار وصيانة ملكيته، مع ما يستلزمه ذلك من التثجيع والترقية والجوائز المادية والمعنوية. • بناء بنكاك معلومات خاص بالمنتج المعرفي فى المجال التربوي في الوطن العربي يسهم في تطوير أنظمة المعلومات التربوية. 


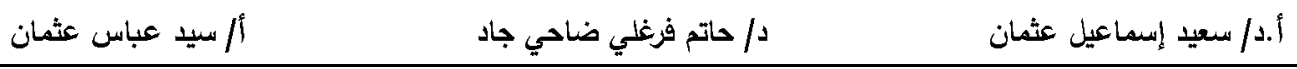

ـ إعفاء الإنتاج الثقافي والمعرفي العربي من كتب وبرامج وأفلام وبرمجيات وصـف ومجلات ومعارض فنية من كل القيود والرسوم الجمركية، وإعطاء التبادل بين الدول العربية لهذه المنتجات أولوية على غيرها. ـ تنشيط مؤسسات الترجمة العربية الحكومية والأهلية من وإلي اللغات الحية، وبـالأخص الجوانب العلمية والإبداعية المستقبلية، ليسهم كل ذلك بفاعلية في تحقيق الإصـلاحات التنموية الثاملة في الوطن العربي. ـ اعتمـاد المؤسسـات المعلوماتيـة وبنـاء مجتمـع المعرفـة والتكنولوجيـة والـربط بـين احتياجات التربية والتعليم وبين إنتاج البحث العلمي في الميدان من خـلا وضع برامج تدربية وتعليمية لإعداد وتصميم وإنتاج وتتفيذ منتجات التكنولوجيا المعلوماتية في كل مستلزمات الحياة، ووضع خطة عربية متكاملة. - إعداد الاستراتيجية العربية للتعلم الإكتروني وتوسيع وتمكين قاعدة استخدامه في التعليم بمراحله وأنواعه كافة، ومن خلال الإفادة من مختلف الوسائل الحديثة، والتجارب

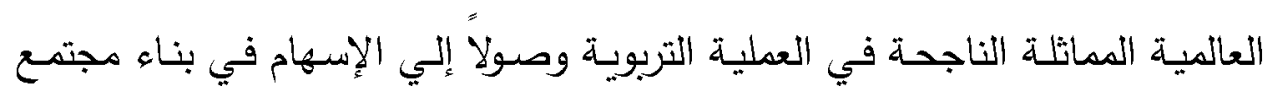

المعرفة.

\section{צ- جهود مصر للتحول نحو مجتمع المعرفة}

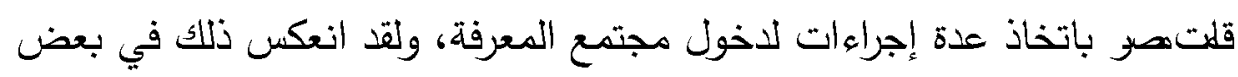
بن النجاحات التي تمهر الطريق لصر المشاركة في مجتمع المعرفة، وكثن يظل هناك المزيد

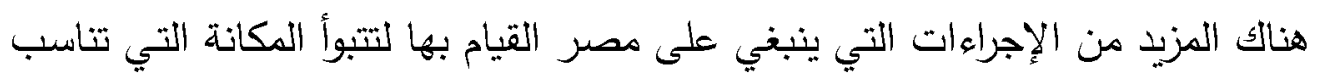
تنلب حجمها ومكانتها الاستراتيجية وتاريخها العريق. ويمكن التعرف على وضع مصر لهر

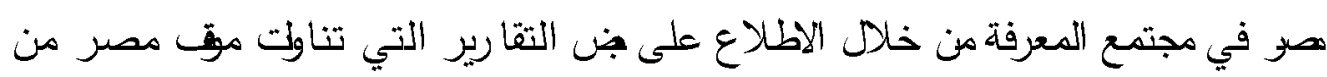
هر من مجتمع المعرفة، وأهم هذه التقارير (تقرير التنافسية الدولية IV + r) و (تقرير

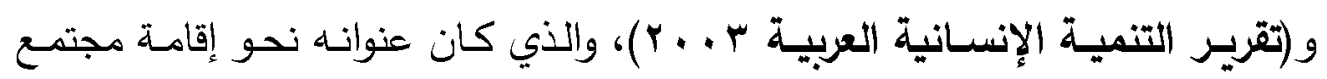

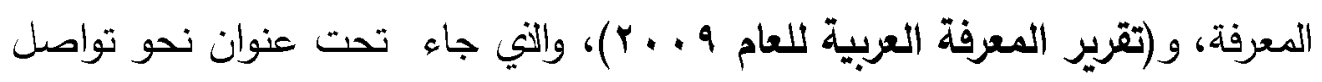




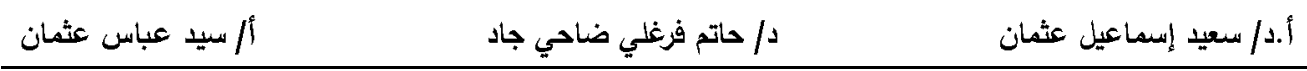

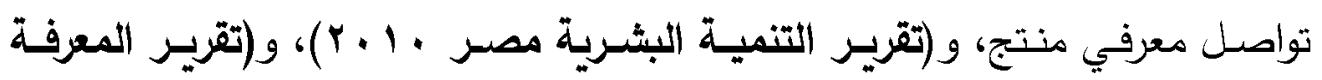

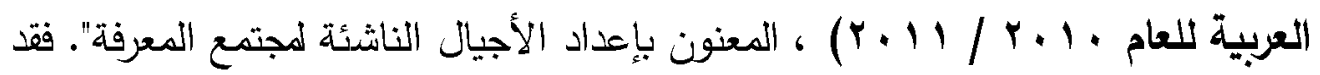
فقد بينت هذه التقارير ما يلي: شهدت مصر خلا ل ل السنوات الأخيرة تقدما ملحوظً في مجمل ما يمكن اعتماده كمؤشرات لثتر المعرفة يين المواطنين، ففي مجال التعليم قلت مصر بعدة جهود، بدءا من تخفي نسبة الأمية انتهاء بعدد الأثخاص لحاصلين على المؤهلات الجامعية العليا؛ فلقد

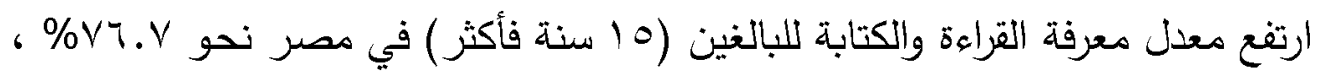
كما قامت مصر بتأمين فرصا عالية لتكوين رأس المال المعرفي الأساسي عند أجيال الأطفال لماعدة على الرغم من محدودية الإمكانيات المادية؛ هيث وصل إجمالي المتعلمين

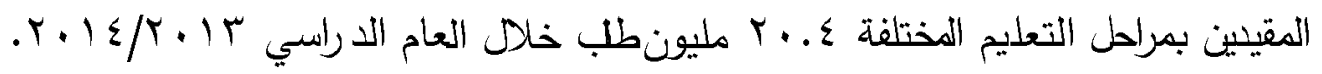

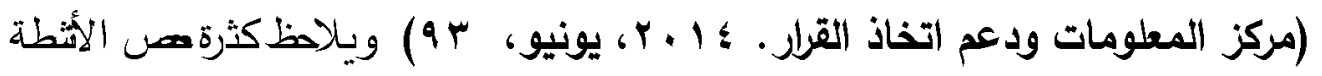
العملية في مرحلة التعليم الأساسي في مصرد

وبالنسبة للتعليم الثانوي توفر مصر فرصـا معقولـة لتكوين رأس المـال المعرفي

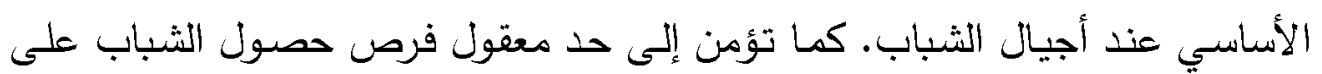
المعارف المتقدمة للمشاركة في مجتمع المعرفة، ولقد بلـغ إجمالي المتعمين المقيدين

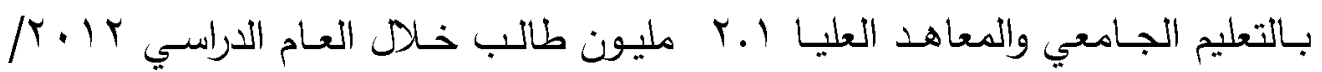

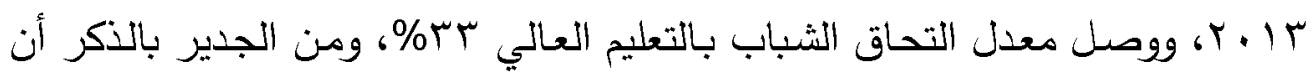
الإنجازات في هذا المجال تفوق الأمكانات المادية. وتزايد عدد الكليات والمعاهد العليا

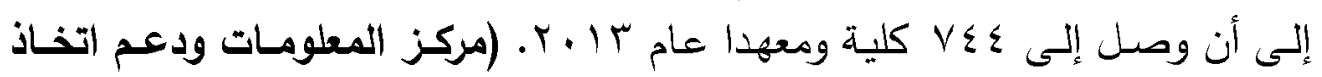

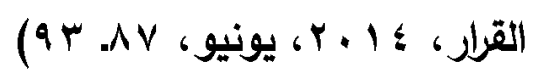
وفيما يخ تكنولوجيا المعلومات والهالات، فإن مصر استحدثت وزارة للاتصالات للإلات وتكنولوجيا المعلومات عام 999 1، ووضعت الأسس لخطة وطنية تهذف إلى ولى إلى تشييد قواعد لمجتمع المعلومات في مصر . كما شهات مصر استثمارات ملموسة من من جب القطاع الخاص، بإنشاء خطوط تجميع لأجهزة الحاسب ذات إمكانيات محدودة 


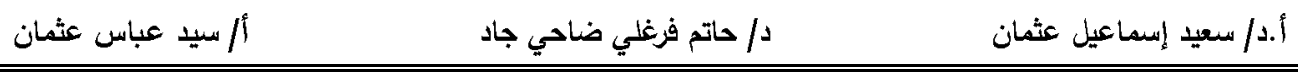

محدودة ومنخفضـة الثمن. ولقد أنشأت مصر هيئة خاصـة لتنميـة صناعة تكنولوجيا المعلومات. كما استطاعت مصر تأمين قدر متوسط من خدمات الحكومة الإكترونية. الإلكترونية.

ولقد بلغ عدد خطوط التايفونات الثابتة 9. ع ا مليون خط فيصر، بمعل 7.

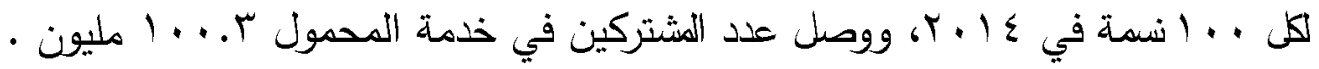
كما شهد عدد الشركات العاملة في مجال الاتصـالات وتكنولوجيا المعلومات ارتفاعا

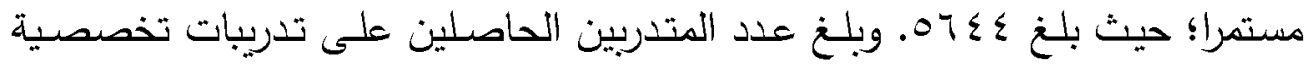
واحترافيـة مـن وزارة الاتصـالات وتكنولوجيـا المعلومـات ب. بـ ألـف متـدرب. (مركـز

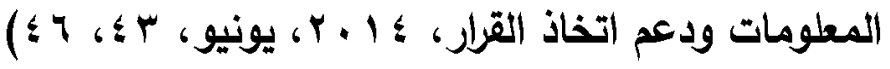
جاءت مصر في المرتبة 11 إضمن مجموعة الـ مبا دولة الصادر عنها مؤشر

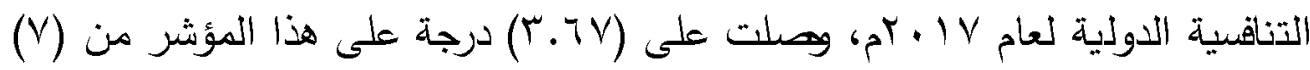
درجات. وهو مؤشر مركب يتكون من ثلاثة مكونات فرعية هي: مكون البيئة ومكون الاستخدام ومكون الاستعداد، هي يقين مؤشر لجاهزية الثبكية ما تحتاج إليه الاتصالات وتكنولوجيا المعلومات من بيئة ملائمة، وسوق تنافسي، وإجراءات تنظيمية متوفرة لكي يكون قاد را على النمو، كما يوضح المؤشر مدى اهتمام المواطنين واستعدادهم لاستخدام تكنولوجيا المعلومات والاتصالات في أنشطتهم اليومية، بالإضافة إلى الاستخدام الفعلي للاتصالات وتكنولوجيا المعلومات (World Economic Forum 2017, 45).

وتقتربصر من المعدل العالمي في مجال استخدام تكنولوجيا المعلومات والإسالات

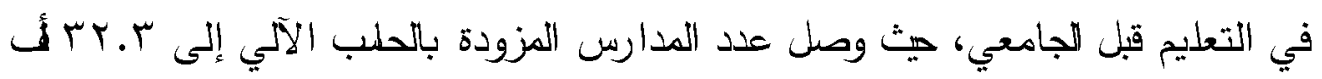

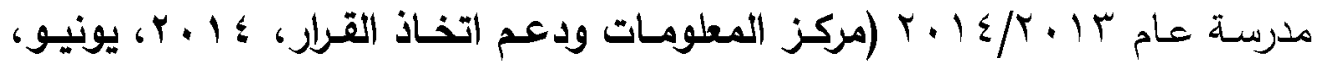
ب 9). ويلاخظ انخفاض أسعار الاخول على الاتترت في هصر إلى حدود تقل عن القيم السائدة في بلدان العالم المتقدمة، وهي أقلى منضف قيمة المتوسط العالمي، وهذا يشير إلى لى إتباع الدولة لسياسات تشجع استخدام الانترنت. 


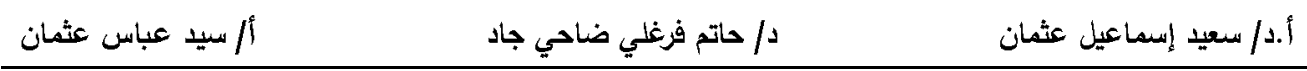

وقد تم تدشين مشروع بنك المعرفة المصري في عـ نوفمبر 10 م با، ويحتوي

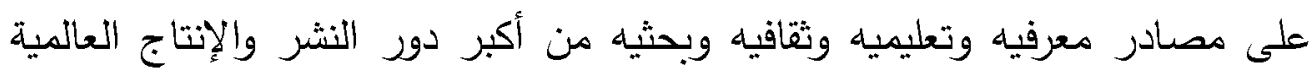

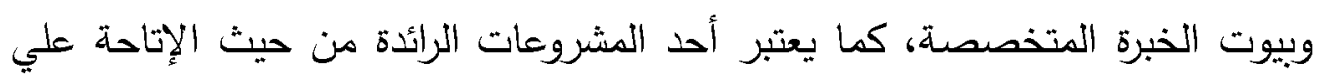
المستوي القومي.

ويحتوي بنك المعرفة المصري علي أربعة بوابات رئيسية وفقا لاهتمامات المستخدمين سواء عموم القراء أو صغار السن أو الطلبة أو الباحثين بالإضافة إلي بولي

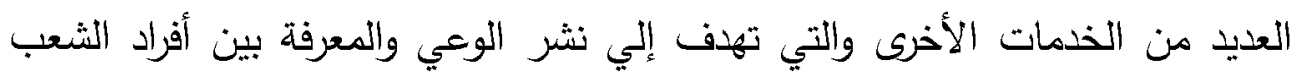
والارتقاء بجودة التعليم من خلا تبسيط العلوم الأساسية وتعزيز جهود البحث العلمي والارتقاء بجودة مخرجات البحث العلمي إلي مستوي التنافسية الدولية. بالنسبة للبوابة الخاصة بالباحثين فهي تحتوي علي آلاف الدوريات العلمية المتخصصة ذات في المجالات البحثية المختلفة بالإضافة إلي مئات الآلاف من الكتب والمراجع العامة والمتخصصة وكذلك قواعد البيانات والأدوات البحثية المتخصصة، فضلاً عن نظام البحث الموحد الذي يتميز بالدقة ومرونة الاستخدام ونظام التصفح الموضوعي لكافة التخصصات (بنك المعرفة المصري، انترنت). وبالرغم من النجاحات التي حققتهامر، فما زال هناك العديد من السلبيات التي تعوق مسيرةصصر في الالثماج في مجتمع المعرفة، منها:

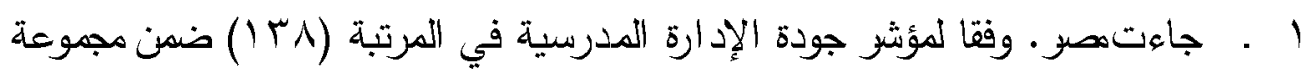

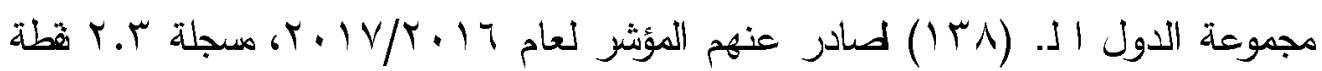

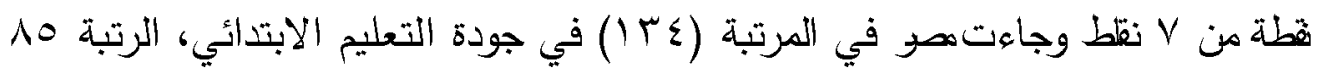

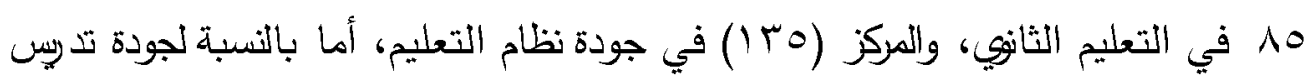

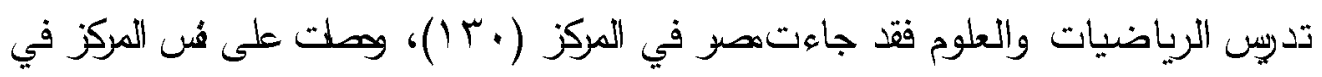

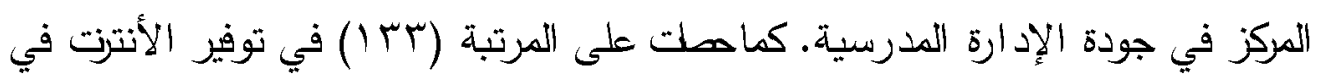

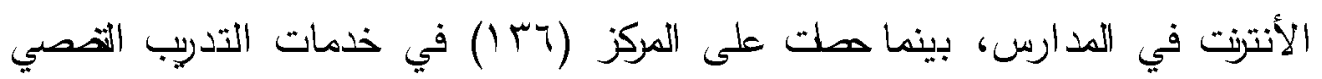

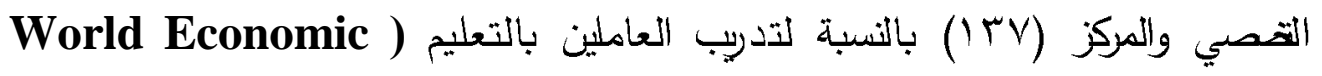


169 - Economic Forum 2017, 168 )، هيث إن المناهج التعليمية في التعليم الأساسي تفتقر إلى الأثطة لخاصة بتنمية القدرة على جمع المعلومات، وتتظيمها، واكتاف مصادر الخطأ، وتحليل المعلومات، وتُسير الظواهر التي تنم عنها، والإحلطة والإحطة بقدرات معلجة المعومات ولظواهر لطبيعية. ويت كل لماك بصلة وثيقة إلى

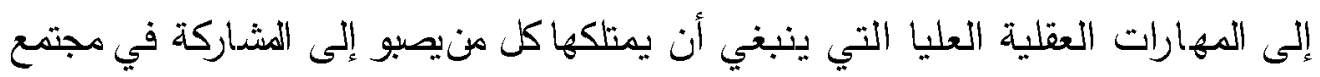
مجتمع المعرفة. r يلاحظ في مقررات المرحلة الثانوبة غيابحص تتمية مهارات التعلم الذاتي والبث عن المعومات وتحليلها وتوليفها، ومهارات التواصل، ومهارات لحياة والمشاركة الاجتماعية، وهي مهارات تعد المتعلم بثكل مباثر للمشاركة الواعية في مجتمع المعرفة.

r ـ الوت الهض لدراسة المواد التعليمية في التعليم الأساسي في فر لا يكفي لتكوين

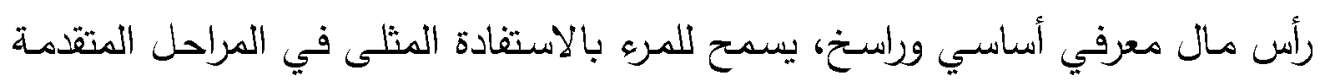
في التعليم والمثاركة الفاعلة مجتمع المعرفة. هيث يتدنى الوق الضض لتعليم مخد المواد الدراسية. ويبذو واضحا أن الوقت المخصص للاراسة في مرحلة التعليم الأساسي يعادل r r أسبوعا، ولقد نتج عن ملك تلني المعدل العاملصص تعلم اللغة العربية عن المعدل الني تمده دول العالم لتعليم اللغة الأم. كما يظل معدل مصر في تعليم اللغات الأجنبية

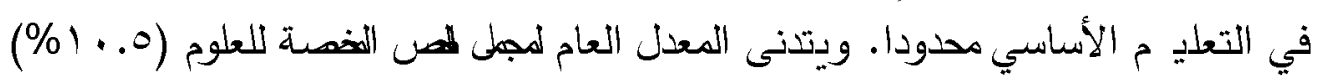

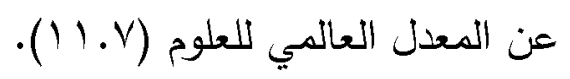

ـ ـ أثـارت نتائج الدراسـة الدوليـة التي أجريت حـول أداء تلاميذ الصـف الثاني الإعدادي في الرياضيات والعلوم في عام r . . T، ضجة كبيرة في الأوساط التربويـة، وأظهرت هذه النتائج أن المعدلات العامة في الرياضيات للتلاميذ لصردين تتدنى بشكل

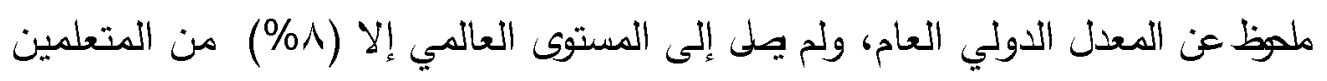
المصرين، هم فقط الذين يمتلكون المعارف التي يقيسها اختبار الرياضيات بينما تفتقد الأغلبية الساحقة منهم هذه المعارف. 


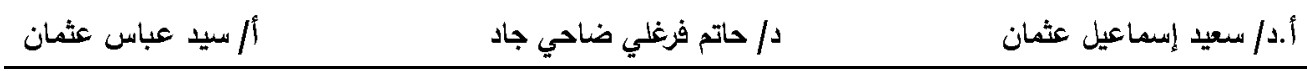

ه ـ هناك تدهور ملحوظ في جودة التعليم العالي خلال العقود الثلاثة الأخيرة الا ان

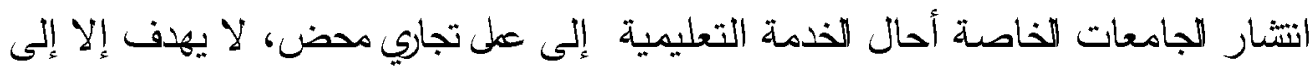

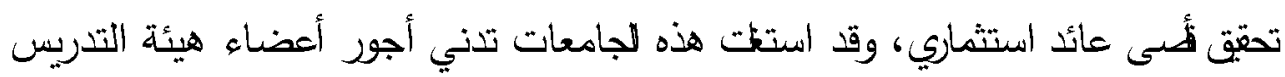

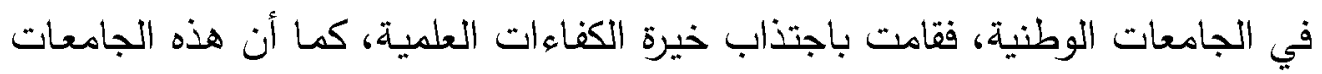
الخاصة، الرامية أساسا إلى الربح، لا تهتم إلا بالمرحلة الجامعية الأولى، حيث البه أعداد

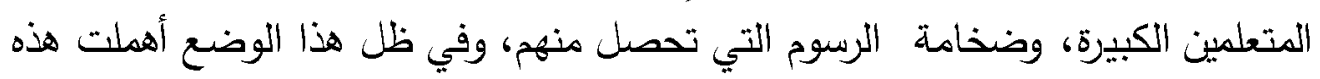
الجامعات الدراسات العليا والبحث العلمي الجاد، نظرا إلى ارتفاع التكلفة، وقلة العائد

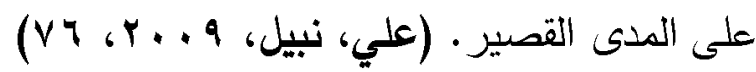

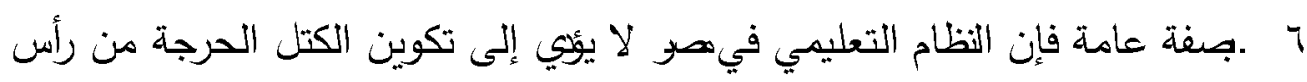
المال المعرفي النوعي التي تحتاجه المجتمع للصي للولوج بثبات في الصناد المعرفة. ولقد

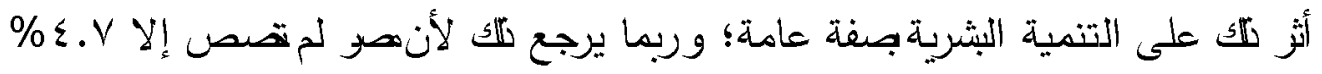

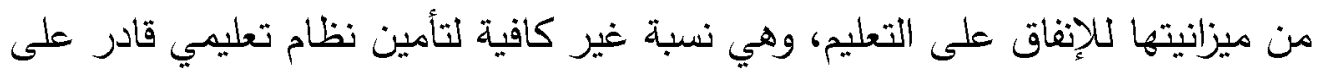
مواجهة تحديات القرن لحلي والحثرين. ومن الأسباب الأخهى لهذا الإخفاق، غياب الرؤية

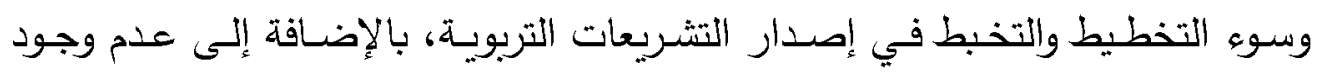
استراتيجية واضحة لتحقيق الأهداف التربوية العامة للتعليم.

ـ وفي مجال تكنولوجيا المعلومات والإلاتلات فإن معدل انتشار أجهزة الحلب الآلي ل V الثضية يقل كثيرا عن المتوسط العالمي. حيث بلغت نسبة الأسر التي لايها حاسب آلي

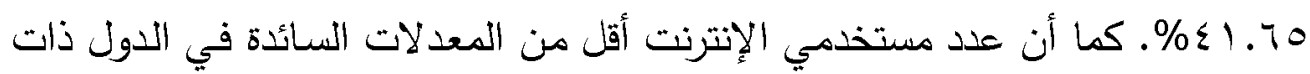

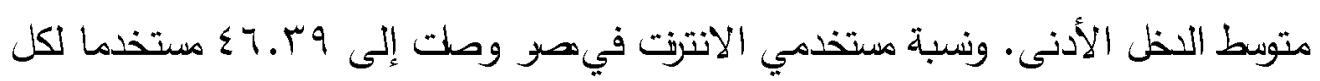

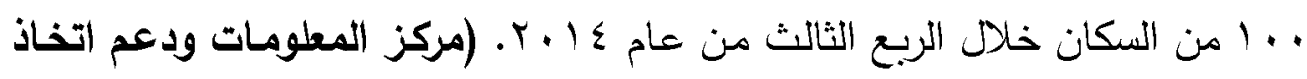

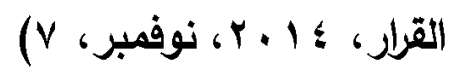

A ـ يتسم استخدام تكنولوجيا المعلومات في مراحل التعليم الجامعي بالضعف، باستنناء باستثناء تعاون جامعة القاهرة مع منظمة اليونسكو في تأسيس كليات افتراضية، وكذلك بكائ وكذلك تعاون جامعة عين شمس مع الجامعة الافتراضية في تقديم مجموعة من المواد 


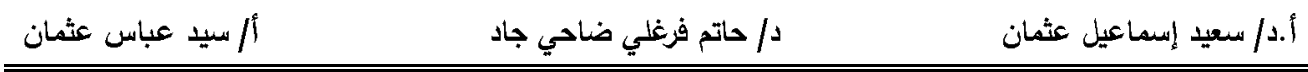

المواد الدراسية عبر الانترت، بالإضافة إلى أن شبكات الإلالات التي يمكن من خلالهها

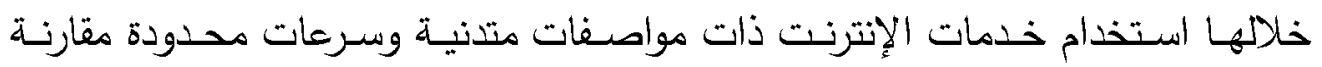
بالاول المتقدمة.

9 يعل في قطاع البرمجيات ما يزيد عن هس وعثرين ألف، إلا أن العائد من صناعة البرمجيات محدود للغاية إذا ما قون بالعائد من هذه الصناعة في دول أخرى. إذ يبلغ مئغ

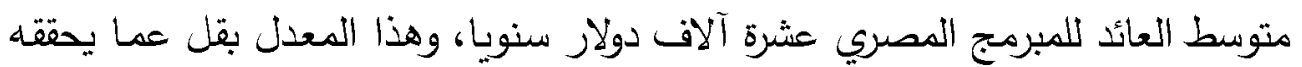
المبرمج الهندي (10 ألف دولار)، كما يقل عما يحققه المبرمج الايرلندي بأشواط كبيرة،

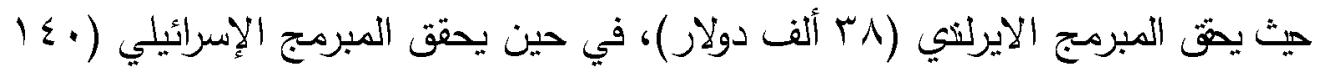

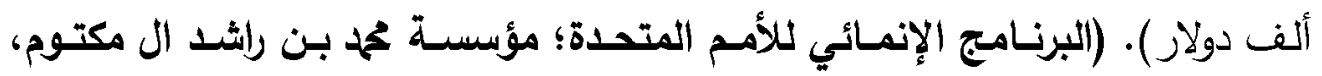

• 1 ـ من المعوقات الأساسية التي تعترض جهود مصر للتحول إلى مجتمع المعرفة،

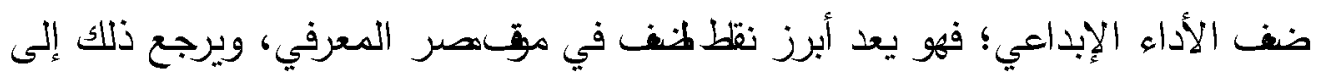
قلة الاستثما رات في مجال البحوث والإبد اع، إذ أن إنفاقهر على على البثث العلمي ضئيل جدا إذا ما قون بدول العالم المتقدم. حيث لا يتجاوز إنفاق مصر على البحث العلمي 0. من الناتج القومي السنوي، وينكك ذلك على محدودية المجهودات التي تقوم بها

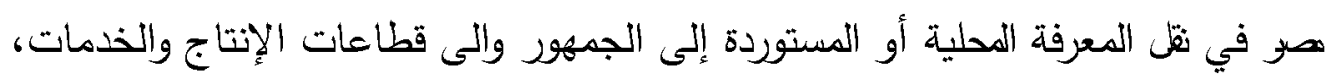
ومن مظاهر هذا لخف محدودية ح ركة النشر والترجمة، وفقر المحتوي الرقمي على شبكة الانترنت. 11 ـ تأتيصر في نيل مظم قوائم مؤشرات المعرفة التي تنشرها المنظمات الدولية، من الدولية، من النشر العلمي إلى الإنتاج الإبداعي، ومن تأليف الكتب، ومن تأليف الكتب

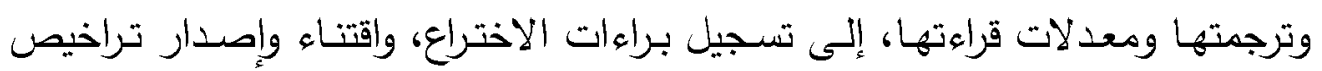

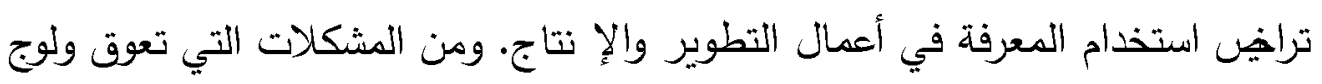
ولوجصر مجتمع المعرفة، هجرة العقول المصرية في ظل النقلة النوعية، وتنامي حركة حركة العولمة، وما صاحبها من اشتداد شراهة الدول المتقدمة على التهام نخب عقول

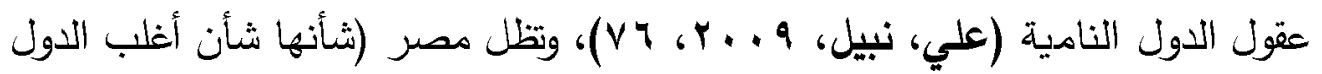




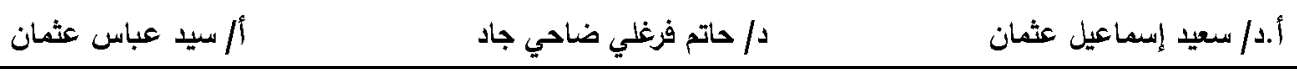

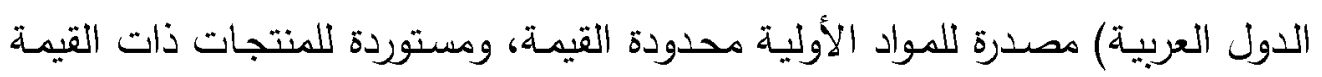
المضافة المرتفعة والمحتوى المعرفي العالي.

مما سنق عرضده، يخح أنهر قد حقت بعض الإنجازات في سبيل الولوج إلى

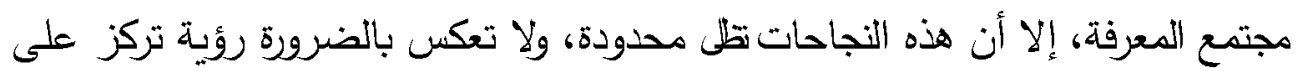

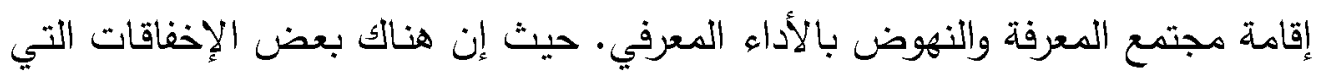
لازت تمثل عقبة كئود أمامصر في التحول نحو مجتمع المعرفة. ولكي تفي مصر بما هو به مطلوب للحاق برب مجتمع المعرفة؛ فلا بد من إجراء تعديلات جذرية وعميقة في منظومة

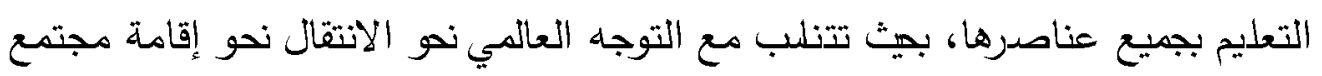
المعرفة، وتثمل هذه التعديلات: استحداث مناهج تناسب مجتمع المعرفة، وتطوير أداء المعلم والموجه الفني، ومحو الأميـة الكمبيوتريـة للعـاملين في مجال التربية والتعليم، وتطوير بيئة التعليم، من خلال توفير المعامل والمكتبات والأجهزة التكنولوجية الحديثة للمدارس، والعمل على تخريج جيل من المبدعين والمبتكرين، كما ينبخي أن تقوم مصر عرير

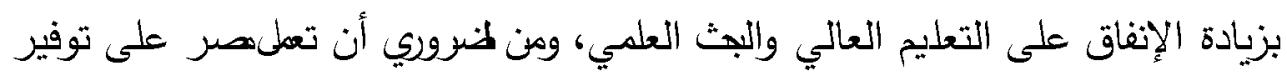
البيئة الملائمة لمجتمع المعرفة، لاسيما توفير لحريات العامة والحرية الاقتصادية والعدالة الاجتماعية من خلال عدالة توزيع نواتج التنمية، وتوفير مناخ ديمقراطي يدعم مشاركة لهية كافة مؤسسات المجتمع في الرقابة واتخاذ القرار • ومن المهم إصلاح شبكات الاتصال في

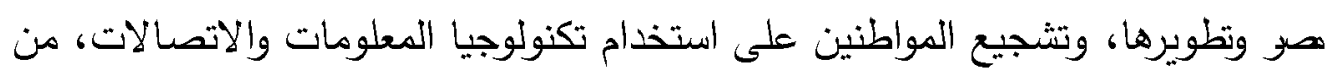

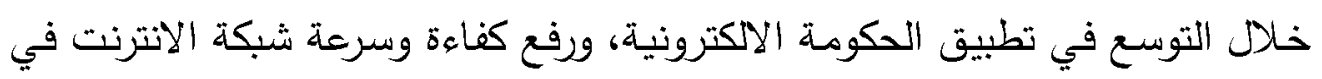
مصر

\section{الخلاصة والتعليق العام:}

يفف الصر لحالي بأنه عصر التقدم العمي الهيلز والتطور لسريع والتغيرات والتغيرات المتلاحقة، والتي من أهمها ثورة المعلومات واللضيالات واستخدام التكنولوجيا التكنولوجيا لحديثة في شتى مجالات لحياة، والتي نضلها أصبح العالم قرية صغيرة، 


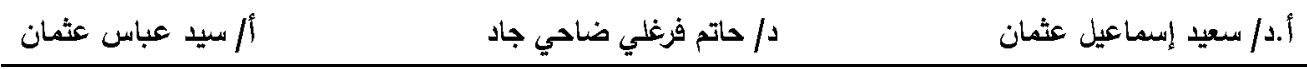

صغيرة، ولقد ألث الثورة التكنولوجية والمعلوماتية الكثير من لحدود والقيود التي كت كت مغروضـة في الماضي على تلفق المعلومات. وبطق على المجتمع في الصر لحالي مجتمع المعرفة؛ وهو المجتمع القائم علي توليد المعرفة, ونشرها, وبوظيفها بكفاءة في جميع دجالات لحياة؛ هيث تؤي المعرفة دورا هاما وأساسيا في التمية البثرية. ولقد برز مجتمع المعرفة كنتجة طبيعية للتطور

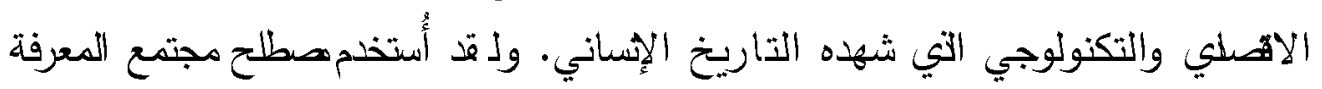
لأول مرة عام 1977.

وتسير المعرفة في دورت تتم عبر ثلاث عمليات، العملية الأولى وهي توليد المعرفة: هيث تطق المعرفة من خلال التفاعل يين لحقلق والمعارف المتوفرة من جهة وبين عقل الإثسان وقدرته على التفكير ويتمثل ثلك في (الإبداع، والابتكار، والتطور)، والعملية الثانية وهي شر المعرفة: ويتم في هذه المرحلة نقل المعرفة بشتى أنواعها عبر (التعليم، والتعلم، والتدرِّ، والمشاركة)، والعملية الثالثة وهي استخدام المعرفة: من خلال توظف المعرفة بكفاءة في كل شئون لحياه (المتجات، ولخدمات، والتطيق)، وهذه الاورة عبارة عن سلسلة مضلة، يؤثز بضها في بض، وهي دورة تسم بالديناميكية والنشلط.

ويجد مجتمع المعرفة أحدث أثكال تطور المجتمع الإنساني، التي مر بعدة تطورات بداية بظهور المجتمع الزراعي، ومرورا بالمجتمع لصناعي، ثم مجتمع المعومات، و صولاً إلى مجتمع المعرفة التي يرنكز بصفة أساسية على سيادة المعرفة.

ومن أبرز ملامح هذا المجتمع سيطرة المعرفة، ويتميز مجتمع المعرفة بهن ثظف توظف وسائل التكنولوجيا لحيثة، والاستفادة مما أحدثته ثورة المعلومات واللضصالات في

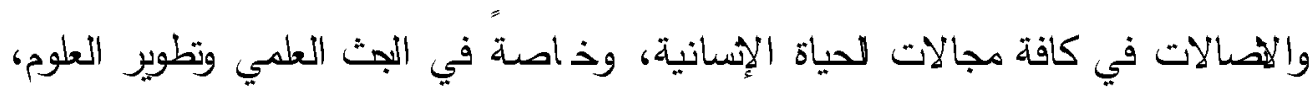




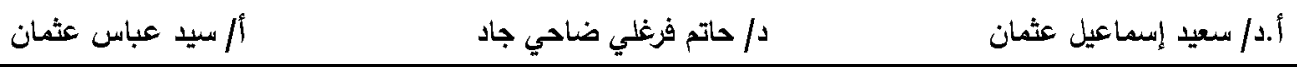

العلوم، والاهتمام بالتعليم والتدرِب، والإعلام والترجمة، والشُر العلمي، والعمل على على تأهيل الكوادر البشرية القادرة على إنتاج المعرفة وحسن توظيفها في ميانين لحياة لإياة البثرية المتعددة. وأهم متطلبات بنـاء مجتمـع المعرفة في جمهوريـة مصر العربية, وهي الاهتمـام بتنمية رأس المال البثري من خلا تطوير وتحسين نوعية التعليم والتدرب؛، والتركيز على إكساب المتعلمين والمواطنين المهارات اللازمة لاكتساب ونثر وإنتاج المعرفة. والعمل على زيادة الميزانية الفمة للتعليم والبحث العلمي، وتشييد بنية تحتية فعالة لتكنولوجيا المعلومات، شهج في شر تكنولوجيا المعلومات والإلات في كل أنحاء مصر ، وإصدار تشريعات تكفل الوصول الثامل للمعلومات والمعرفة. وفي مجتمع المعرفة ينبني العمل على اكساب المعلمين والمتعلمين مهارات إنتاج المعرفة ليتمكنوا من التعلث مع تحدياتها، والتحول من التعلم من أجل المعرفة إلى التعلم من أجل العمل ومن التعلم من التعايش مع الآخرين إلى التعلم من أجل أن نكون.

كما يتطلب التحول التربوي نحو مجتمع المعرفة بناء منظومة بحث وتطوير وعلم وتكنولوجيا للإبداع والابتكار فاعلة، ويتمثل هدف هذه المنظومسة في رفع المستوى الآصلي والمعرفي في آن واحد, وبناء بنك معلومات خاص بالمنتج المعرفي في المجال التربي يسهم في تطوير أنظمة المعلومات التربوية. وتنشيط مؤسسات الترجمة من وإلي اللغات الحية، وبالأض الجوانب العلمية والإبداعية المستقبلية، ليسهم كل ذلك بفاعلية في تحقيق الإصلاحات التنموية الثاملة. والربط بين احتياجات التربية والتعليم وبين إنتاج البحث العلمي في الميدان من خـلال وضـع بـرامج تدربيية وتعليمية لإعداد وتصميم وإنتاج وتنفيذ مذتجات التكنولوجيا المعلوماتية في كل مستلزمات الحياء. 
أ.د/ سعيد إسماعيل عثمان انتهاء بزيادة عدد الأثخاص لحاصلين على المؤهلات العليا. كما أن مناهج التعليم للصرية تقترب من المناهج العالمية في الرياضيات والعلوم. وفيما غض تكنولوجيا

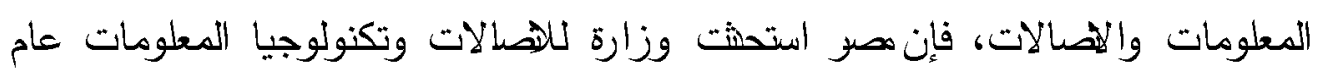
1999، ووضعت خطة تهدف إلى تثييد قواعد لهتمع المعرفة. بالإضافة إلى تششين

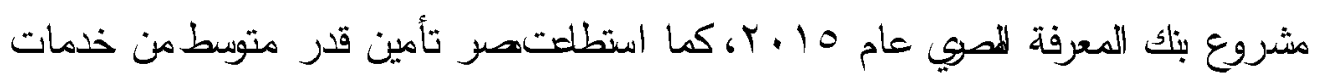
لحكومة الإكترونية، ومع ذلك ما زال الكثير أمامصر للحاق بالدول المتقدمة في مجتمع المعرفة. 


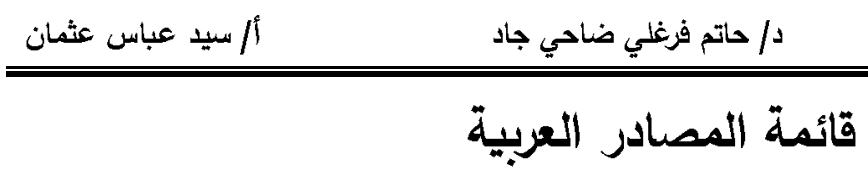

ا . إسماعيل، عفاف عبدالله أحمد. (N . . (Y). "التعلم الإكتروني في مجتمع المعرفة من منظور إسلامي". المؤتمر الاولي الثالث (دور التعلم الإلكتروني في تعزيز مجتمعات المعرفة) المنعقد في الفترة من 7 حتى م أبريل. البحرين.

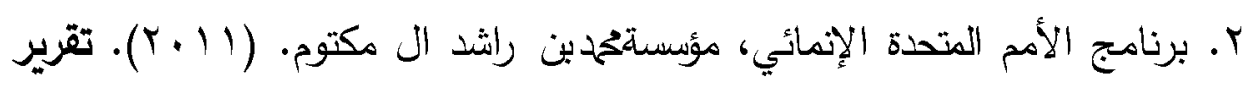

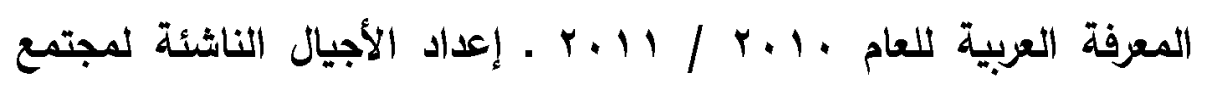
المعرفة. دبي: شركة دار الغريز الطباعة والثر.

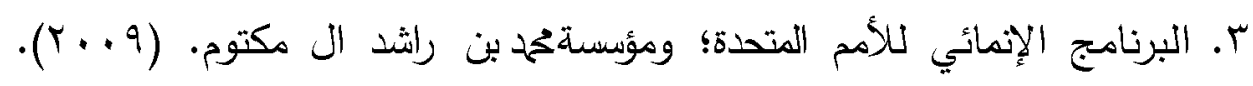
تقرير المعرفة العربية للعام 9 + . ب ندو تواصل معرفي منتج. دبي: شركة دار الغربر لطباعة والثير.

ح. البرنامج الإنمائي للأمم المتحة. (ب . . (ب). تقرير التنمية الإنسانية العربية.

$$
\text { نيودورك: المكب الإقليمي للاول العربية. }
$$

ه. البرنامج الإنمائي للأمح المتحدة ومعهد التخطيط القومي. (. (ب). تقربر

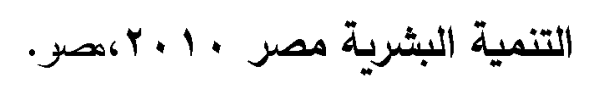

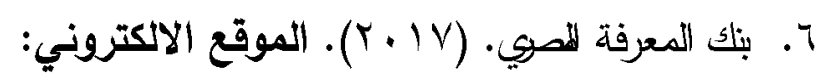

استرجت في تاريخ ا أبريل http://www.ekb.eg/about- us

$$
.+1 \mathrm{~V}
$$

V. توظر، ألن. (797) . ب9اء حضارة جديدة. (سعد زهران، مترجم). القاهرة:

$$
\text { مركز المحروسة للبحوث والتدريب. }
$$

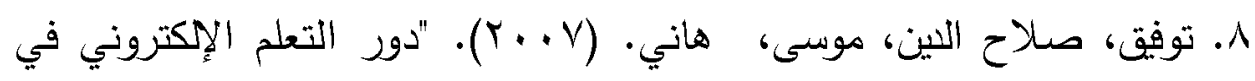
بناء مجتمع المعرفة العربي". مجلة كلية التربية بشبين الكوم، جامعة المنوفية،

$$
\text { العدد r. }
$$




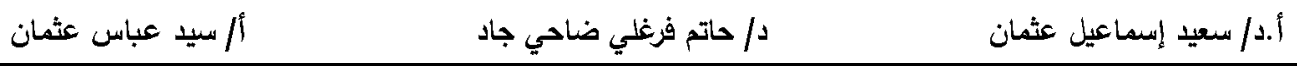

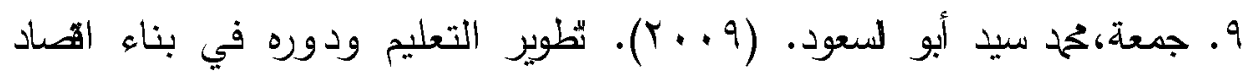
المعرفة". المؤتمر الاولي الأول للتعليم الإكتروني والتعليم عن بعد ـ صناعة

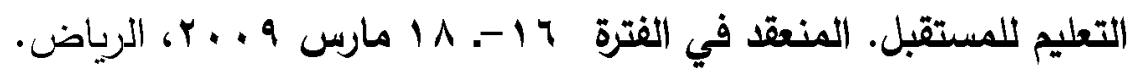

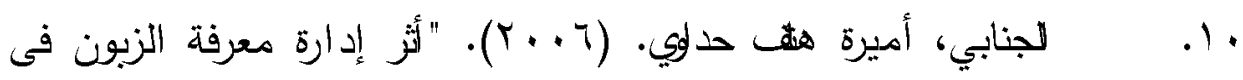
تحقق التفوق التنلفي". رسالة ماجستير. كلية الإدارة والإهاد، جامعة الكوفة.

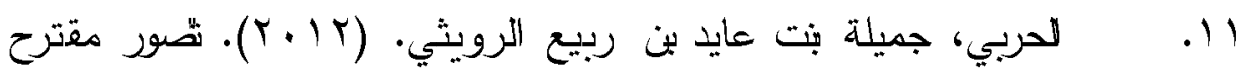
لتفعيل وظت الإشراف التربوي في ضوه الاثجاهات التربوية لحديثة ومتطلبات مجتمع المعرفة". رسالة دكتوراه. كلية التربية، جامعة أم التى.

Y ا. حسانة، محيى اللين. (T . . Y، أغطس). "التحول من مجتمع المعلومات إلى مجتمع المعرفة". مجلة مكتبة الملك فها الوطنية، المجلد با (العدد Y)،

$$
. v \cdot-0 \text {. }
$$

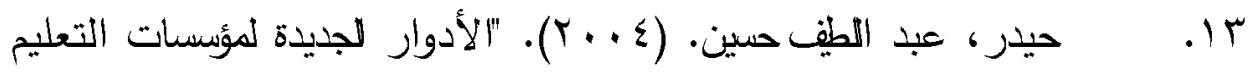
في الوطن العربي في ظل مجتمع المعرفة". مجلة كلية التربية جامعة الإمارات

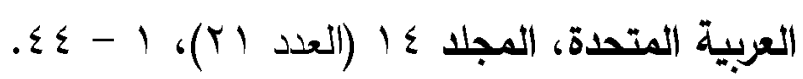

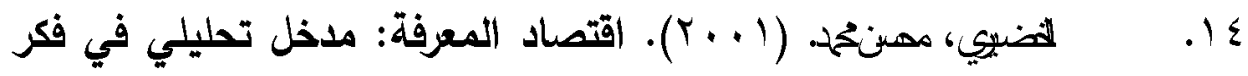
وفلسفة ومكونات اقتصاد عصر ما بعد الحداثة والثولوج إلي عصر تدويل الاقتصاد الجديد والعولمة الاجتياحية. القاهرة: مجموعة النيل العربية لطباعة والثشر. 


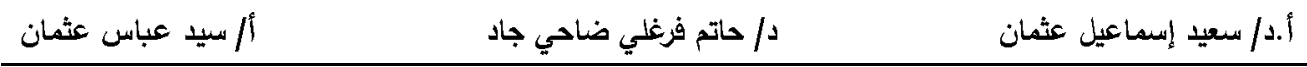

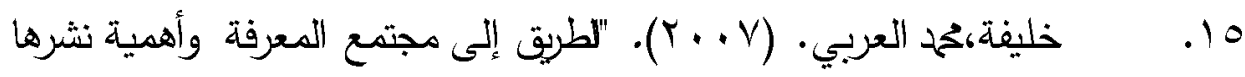
باللغة العربية". مقدمة مجد مؤتمر المجلس الأعلى للغة العربية بالجزائر الطريق نحو مجتمع المعرفة وتوطينها باللغة العربية، الجزائر.

ربيع،محم عبد العزيز • (0. . ب). "الإبداع والمعرفة في عصر العولمة". .17 المؤتمر العلمي العربي الرابع للموهوبين والمتفوقين المنعقد في الفترة من

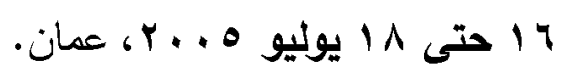

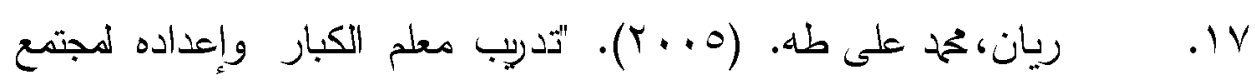
المعرفة". المؤتمر السنوي الثالث لمركز تعليم الكبار بجامعة عين شمس بالاثتراك مع المنظمة العزبية للتربية والثقافة والعلوم "معلم الكبار في القرن الحادي والعشرين". المنعقد في الفترة من بr حتى ؛ ب ابريل ه ه . r، مركز

$$
\text { تعليم الكبار بجامعة عين شس }
$$

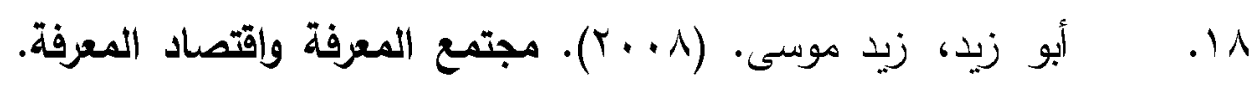
استرجت http//zaidabuzaid.jeeran.com

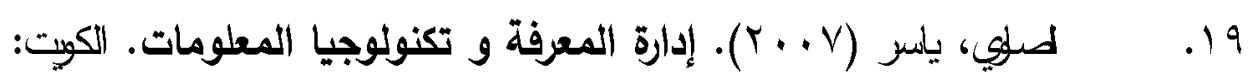
دار لنحاب للشّر والتوزيع.

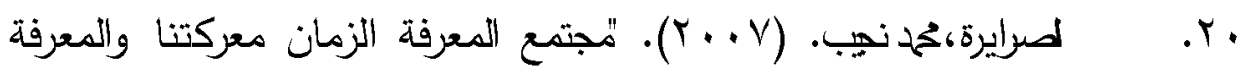
سلاحنا". المؤتمر العلمي الاوبي الأول لكلية الآداب والعلوم الاجتماعية بعنوان "مجتمع المعرفة: التحديات الاجتماعية والثقافية واللغوية في العالم

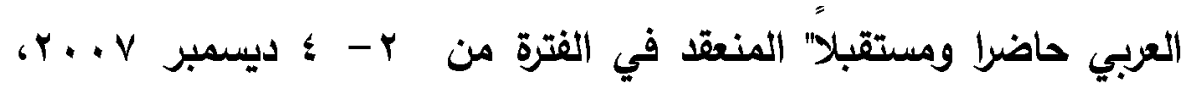
جامعة السلطان قابوس، مسقط. 


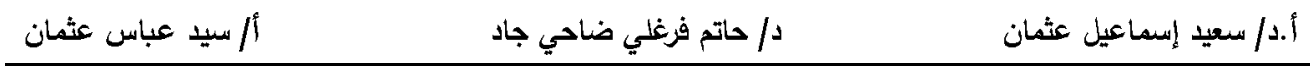

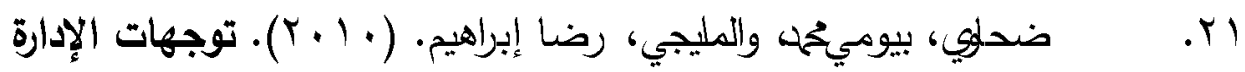
التربوية الفعالة في مجتمع المعرفة. القاهرة: دار الفكر العربي.

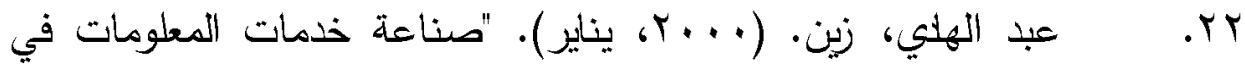
صر دراسة كل من الطاعبن العام والخاص". مجلة الاتجاهات الحديثة في

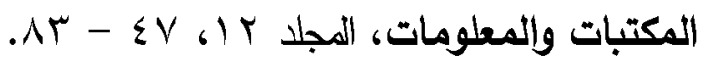

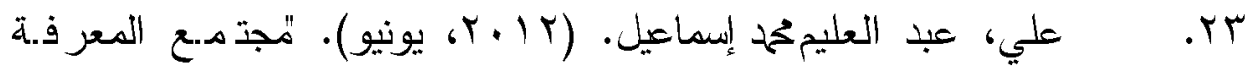

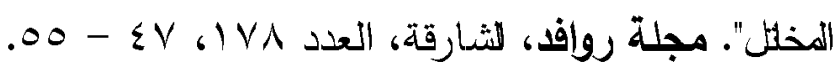

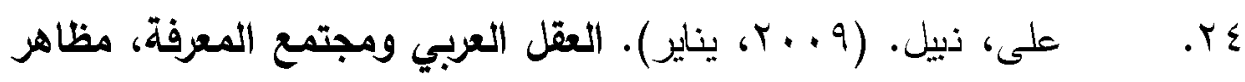
الأزمة واقتراحات بالحلول. سلسلة عالم المعرفة، 9؟ب، الكوبت: الملمس الوطني للثقافة والفنون والآداب.

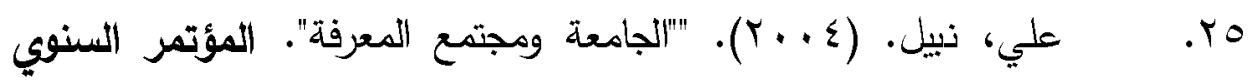
الأول للمركز العزبي للتعليم والتتمية بالتعاون مع جامعة عين شمس في الفترة من ب حتى ه مايو ؛ + . ب، القاهرة.

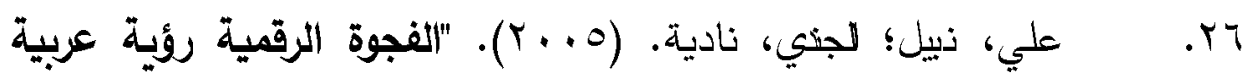
لمجتمع المعرفة". سلسلة عالم المعرفة، ^اس، الكوبت: المهل الوطني للثقافة

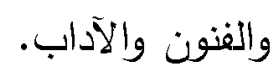

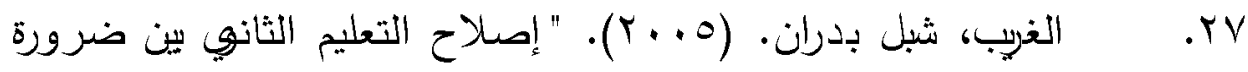
المشاركة المجتمعية ومتطلبات مجتمع المعرفة". المؤتمر العلمي السادس المثاركة وتطوير التعليم الثانوي في مجتمع المعرفة، المركز القومي للبحوث التزبوية والتنمية، القاهرة. 


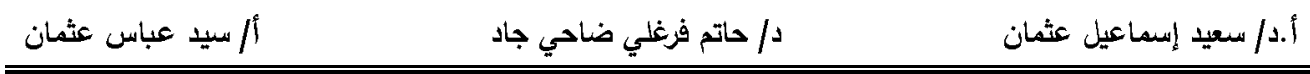

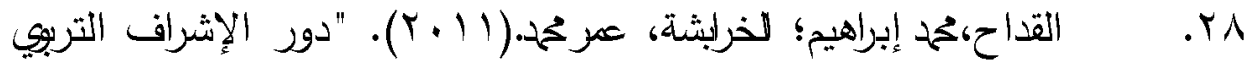

في توجيه عمليات التعلم نحو اهصاد المعرفة في المدارس الأردنية". مجلة

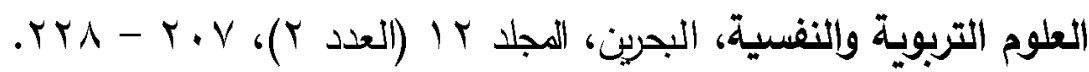

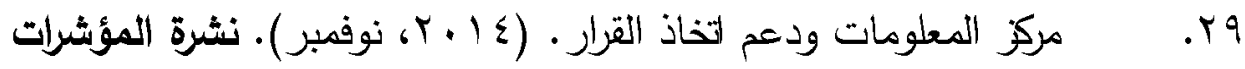
الاقتصادية والاجتماعية لجمهورية مصر العربية. القاهرة.

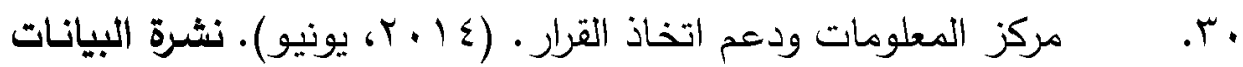
القومية. القاهرة.

اس. مرياتي تحمد. (د.ت.). التطور التكنولوجي لاستدامة الصناعة في ظل

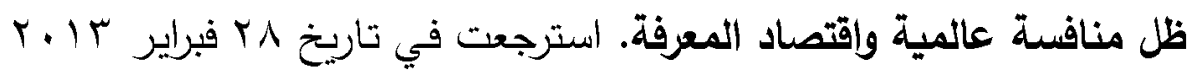
r.IT http://www. mafhoum.com/syr/articles/mrayati/mrayati.htm

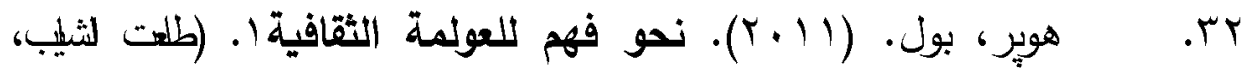
مترجم). القاهرة: المركز القومي للترجمة.

\section{English Resources}

33.Brine, Jacky (2006). "Lifelong learning and the knowledge economy: Those that we know and those that do not: The discourse of the European Union". British Educational Research Journal, 32 (5), 649 - 665.

34.Britz , j.; Lor, p; Coetzee, I . \& Bester , A . (2006). "Africa as a knowledge society : a reality check" . The International Information Library Review, 38, 25 - 40. 


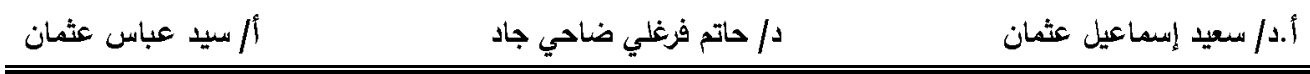

35.Gilbert, Jane. (2006). Catching the Knowledge Wave? The knowledge society and the future of education. New Zealand, Wellington: NZCER Press.

36.Kring, Bettina. (2006, November). "The sociological perspective on the knowledge-based society: assumptions, facts and visions". Enterprise and Work Innovation Studies, 2, 9 - 19.

37.Laudan \& Laudan. (2000). Management Information System (6th. ed.). Canada: Prentice-Hall.

38.Lord, Kristin M. (2008). A New Millennium of Knowledge: The Arab Human Development Report on Building a Knowledge Society. Brookings, Washington DC: Saban Centre.

39.Nokkala, Terhi. (2007). "Constructing the Ideal University The internationalization of higher education in the competitive knowledge society". PhD thesis, Presented to Faculty of Economics and Administration, Finland: University of Tampere, 40.Slaus , I, (2007). "Building a knowledge - based society : the case of South East Europe" .Futures, 39, 986 - 996 . 
41.Välimaa, Jussi \& Hoffman, David. (2008, Sep.). "Knowledge Society Discourse and Higher Education". Higher Education, 56 (3), 265 - 285.

42.Webster, Frank. (2002). Theories of the information society $\left(2^{\text {nd }}\right.$. ed. $)$. London: Routledge.

43.World Economic Forum .(2017).The Global Competitiveness Report 2016-2017, Geneva, World Economic Forum 